\section{RESEARCH ARTICLE \\ 10.1029/2019JC015373 \\ Multisource Bayesian Probabilistic Tsunami Hazard Analysis for the Gulf of Naples (Italy)}

Key Points:

- A comprehensive methodology is proposed to evaluate the probabilistic hazard posed by different tsunamigenic sources

- A modular Bayesian methodology is used to treat different levels of epistemic uncertainty in a case study - Three major tsunamigenic sources (earthquakes, submarine landslides, and volcanic pyroclastic flows) are analyzed in the Gulf of Naples, Italy

Correspondence to:

Anita Grezio,

anita.grezio@ingv.it

Citation:

Grezio, A., Cinti, F. R., Costa, A., Faenza, L., Perfetti, P.,

Pierdominici, S., et al. (2020)

Multisource Bayesian probabilistic

tsunami hazard analysis for the Gulf

of Naples (Italy). Journal of

Geophysical Research: Oceans, 125,

e2019JC015373. https://doi.org/10

1029/2019JC015373

Received 14 JUN 2019

Accepted 15 JAN 2020

Accepted article online 21 JAN 2020

(C)2020. American Geophysical Union. All Rights Reserved.

\author{
Anita Grezio $^{1}$ (D) , Francesca Romana $\operatorname{Cinti}^{2}$ (D), Antonio Costa ${ }^{1}$ iD, Licia Faenza ${ }^{1}$ (D),

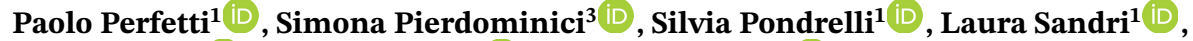 \\ Pablo Tierz ${ }^{1,4}$ (iD) Roberto Tonini $^{2}$ iD , and Jacopo Selva $^{1}$ (D)
}

${ }^{1}$ Istituto Nazionale di Geofisica e Vulcanologia, Bologna, Italy, ${ }^{2}$ Istituto Nazionale di Geofisica e Vulcanologia, Roma, Italy, ${ }^{3}$ Helmholtz-Zentrum Potsdam Deutsches GeoForschungsZentrum, Potsdam, Germany, ${ }^{4}$ British Geological Survey, The Lyell Centre, Edinburgh, UK

\begin{abstract}
A methodology for a comprehensive probabilistic tsunami hazard analysis is presented for the major sources of tsunamis (seismic events, landslides, and volcanic activity) and preliminarily applied in the Gulf of Naples (Italy). The methodology uses both a modular procedure to evaluate the tsunami hazard and a Bayesian analysis to include the historical information of the past tsunami events. In the Source Module the submarine earthquakes and the submarine mass failures are initially identified in a gridded domain and defined by a set of parameters, producing the sea floor deformations and the corresponding initial tsunami waves. Differently volcanic tsunamis generate sea surface waves caused by pyroclastic density currents from Somma-Vesuvius. In the Propagation Module the tsunami waves are simulated and propagated in the deep sea by a numerical model that solves the shallow water equations. In the Impact Module the tsunami wave heights are estimated at the coast using the Green's amplification law. The selected tsunami intensity is the wave height. In the Bayesian Module the probabilistic tsunami analysis computes the long-term comprehensive Bayesian probabilistic tsunami hazard analysis. In the prior analysis the probabilities from the scenarios in which the tsunami parameter overcomes the selected threshold levels are combined with the spatial, temporal, and frequency-size probabilities of occurrence of the tsunamigenic sources. The prior probability density functions are integrated with the likelihood derived from the historical information based on past tsunami data. The posterior probability density functions are evaluated to produce the hazard curves in selected sites of the Gulf of Naples.
\end{abstract}

Plain Language Summary Probabilistic analyses are essential to estimate the natural hazards caused by infrequent and devastating events and to elaborate risk assessments aiming to mitigate and reduce the impact of the natural disasters on society. Probabilistic tsunami hazard analyses use procedures that trace and weight the different tsunami sources (submarine earthquakes, aerial/submarine slides, volcanic activity, meteorological events, and asteroid impacts) with varying probability of occurrence. The scope of the present methodology is the reduction of possible biases and underestimations that arise by focusing on a single tunamigenic source. The multisource probabilistic tsunami hazard analysis is applied to a real case study, the Gulf of Naples (Italy), where relevant threats due to natural events exist in a high densely populated district. The probabilistic hazard procedure takes into account multiple tsunamigenic sources in the region and provides a first-order prioritization of the different sources in a long-term comprehensive analysis. The methodology is based on a Bayesian approach that merges computational hazard quantification (based on source-tsunami simulations) and past data, appropriately including in the quantification the epistemic uncertainty. For the first time a probabilistic analysis of the tsunami hazard in the region is presented taking into consideration multiple tsunamigenic sources.

\section{Introduction}

In general, hazards due to multiple events may exponentially increase the impact of disasters on society with respect to the hazards that consider separately different events (Faenza et al., 2013; Marzocchi et al., 2012; Selva, 2013; Tierz et al., 2017). Similarly, the probabilistic tsunami hazard assessment should not be focused on one type of tsunami source only, but different potential sources should be considered and combined 
together to provide a complete and unbiased assessment (Grezio et al., 2015). In this multihazard perspective we propose a comprehensive methodology taking into account different types of tsunamigenic sources such as submarine earthquakes, mass failures, and pyroclastic density currents. Even though potentially significant, at this level we do not account for their potential interaction. The study has the main following purposes: (a) dealing simultaneously with the different principal types of tsunamigenic sources in a coherent multidisciplinary probabilistic framework and (b) evaluating the long-term comprehensive tsunami hazard in a Bayesian analysis, hence merging prior information-for example, modellng — and past/historical data. This scheme is here applied in the context of the multirisk problem in the Campania region (Faenza et al., 2017; Perfetti et al., 2018; Sandri et al., 2018; Tierz et al., 2017, 2018). Natural hazards have posed relevant threats to the city of Naples and the surrounding areas. In the last centuries, earthquakes (Locati et al., 2016) and volcanic eruptions (Guidoboni \& Boschi, 2006) have been reported at significant level of intensity, while tsunami events are described as less severe (Maramai et al., 2014). However, human presence and coastal anthropogenic activities increased significantly in modern times, requiring to assess tsunami hazard caused by different types of potential tsunamigenic sources (Grezio et al., 2017) at global (Davies et al., 2017; Løvholt et al., 2015; Paris et al., 2014), regional (Selva et al., 2016), and local level (e.g., the ByMuR Italian Project: Bayesian Multi-Risk Assessment: A case study for natural risks in the city of Naples; Lorito et al., 2015, and Volpe et al., 2019).

Lorito et al. (2008) and Tinti et al. (2005) examined the main tsunamigenic structures, respectively, in the Algeria-Tunisia Offshore Source Zone and Southern Tyrrhenian Source Zone. Both seismic zones are expected to generate significant tsunamis on the Tyrrhenian coasts caused by submarine earthquakes. Recently, probabilistic tsunami hazard in the case of seismic sources was evaluated in the Mediterranean Sea providing probabilistic hazard models (Lorito et al., 2015; Selva et al., 2016; Sørensen et al., 2012).

Additional potential sources of tsunamis, which could affect the Neapolitan coast, are the debris avalanches (Tinti et al., 2011). The consequences of an Ischia debris avalanche were explored as single scenarios by Tinti et al. (2011) and Paparo and Tinti (2017). A few studies for long- and short-term tsunami hazard were carried out in the region including both submarine mass failures and submarine earthquakes (Grezio et al., 2015; Selva et al., 2019).

In historical time the volcanic events generating tsunamis were related to the Somma-Vesuvius activity. Pliny the Younger reported that sea withdrew during the catastrophic eruption that destructed the city of Pompeii and the surrounding areas (79 CE). Anomalous sea waves were observed in the Gulf of Naples during the 1631 eruption (Maramai et al., 2014). Tinti et al. (2003) proposed scenarios with low-density (dilute) pyroclastic flows that confirmed relatively modest oscillations in the Gulf of Naples. However, a probabilistic study of tsunamis caused by volcanic activity is not present in the region. Only recently, Paris et al. (2019) implemented a preliminary probabilistic framework for tsunamis generated by underwater volcanic explosions in the submarine part of the Campi Flegrei caldera near Naples.

The goal of this paper is to illustrate a potential strategy for integrating different sources of tsunami in a real case study, providing a first-order prioritization of the different sources.Therefore, basic assumptions are made in the whole hazard quantification process, in order to reduce the computational effort and simplify the discussion.

In section 2 the methodology is presented in a modular and suitable form for further improvements and tsunami assessments. In section 3 the different types of potential tsunamigenic sources are discussed, the tsunami waves modeled, and the coastal wave heights computed. In section 4 the prior analysis is estimated in a multisource frame considering the probabilities of the tsunami waves from the simulated scenarios, then the likelihood updates prior results on the basis of the historical catalogs and past data, and finally the posterior analysis is accomplished by combining the prior analysis with the likelihood to produce the Bayesian tsunami hazard for the time window of 50 years with the hazard results at selected sites in the Gulf of Naples. In section 5 results and conclusions are discussed.

\section{Methodology}

The probabilistic tsunami hazard analysis $(P T H A)$ is defined by the probability $p(Z \geq z, \Delta t)$ that a selected value $z$ of a parameter representing the tsunami intensity $Z$ is overcome in a certain exposure time $\Delta t$ at a 


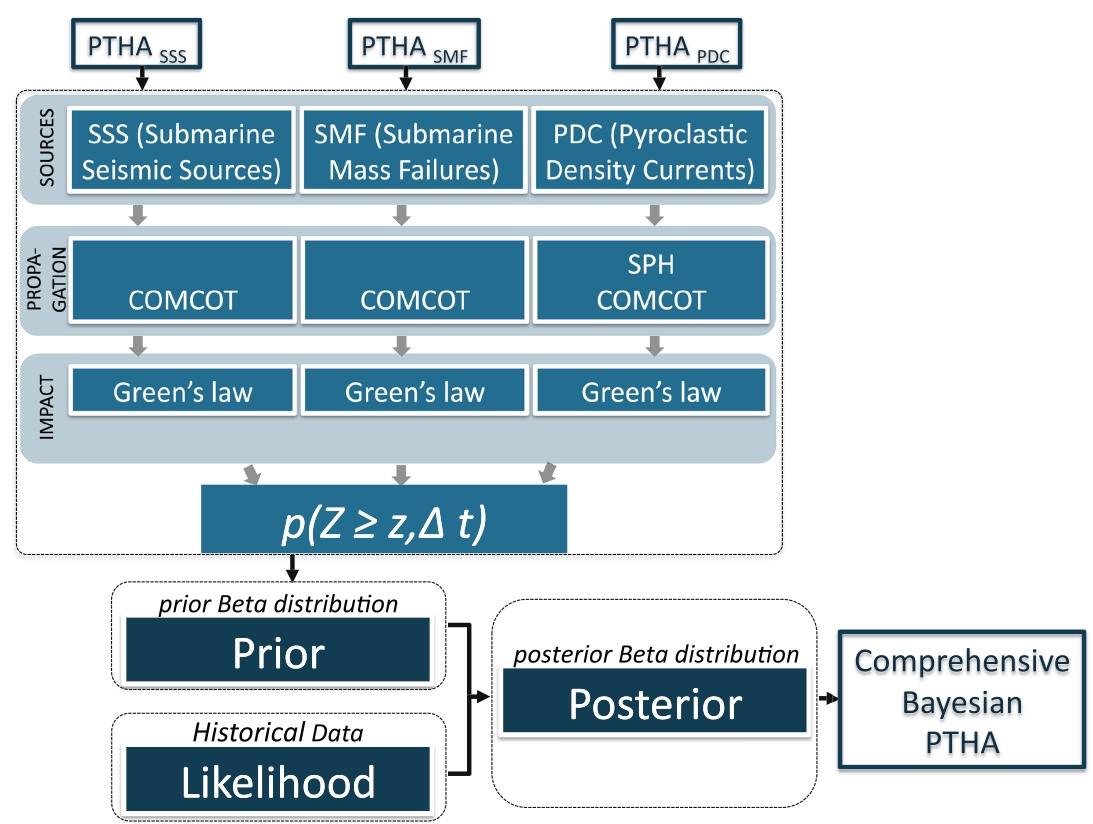

Figure 1. The modular schema used for the computation of the long-term comprehensive Bayesian PTHA in case of different types of sources. The procedure evaluates the PTHAs for SSSs, SMFs, and PDCs separately. Initially, the three different data sets of potentially tsunamigenic events produce the relative three sets of initial tsunami waves. Those initial waves are propagated by the numerical model COMCOT (Cornell Multi-grid Coupled Tsunami Model) up to the depth of $50 \mathrm{~m}$ for both SSSs and SMFs. In the case of the PDCs the additional model SPHysics (Smoothed Particle Hydrodynamics) is used to compute the initial tsunami waves, which are subsequently propagated by the COMCOT model at the $50 \mathrm{~m}$ isoline. Then the wave heights are evaluated by the Green's law at the coastal points of the Gulf of Naples. First, the prior module computes the Beta distributions on the basis of the the probabilities to overcome the selected $z$ threshold levels and the temporal, spatial, and frequency-size source probabilities. Second, the likelihood module includes the historical information in the probabilistic analysis. Finally, the posterior module evaluates the Bayesian posterior Beta distributions in each point of the coastal sites in the Gulf of Naples to provide the PTHA.

given coastal location. In general, $Z$ refers to the tsunami intensity (e.g., runup, velocity, energy, moment flux, and wave height) and $z$ is the threshold value used in the hazard analysis.

Submarine Seismic Sources ( $S S S \mathrm{~s}$ ), Rock Avalanches ( $R A \mathrm{~s})$, Submarine Mass Failures ( $S M F \mathrm{~s}$ ), Pyroclastic Density Currents (PDCs), and Submarine Volcanic Explosions (SVEs) are the major types of sources generating tsunamis in the Gulf of Naples. In the present study we focus on three types of sources: SSSs, $S M F$, and PDCs. More general studies are the objective of future works. For each specific source type (ST) we define a set of potentially tsunamigenic source events $(S E s)$ in the region considering a range of locations, magnitudes, and intensities. For example, the seismic $S T$ includes a large number of submarine earthquakes $S E$ s with the relative magnitudes, locations, and fault parameters. Each $S E$ is a specific physical source and produces a tsunami scenario with the corresponding values of the $Z$ parameter at the coastal sites. In the following analysis, each $S T$ constructs the relative $P T H A_{i}(i=S S S, S M F, P D C)$. The three $P T H A_{i}$ serve to evaluate the multisource $P T H A$ in case of different types of tsunamigenic sources. The long-term comprehensive PTHA includes also the historical data through the Bayes' theorem. Figure 1 reports a modular scheme of the PTHA and represents an extension of the scheme for the seismic case by Grezio et al. (2010).

\subsection{PTHA for Different Types of Tsunamigenic Sources}

Given the $i$ th tsunamigenic source type $S T_{i}(i=S S S, S M F, P D C)$, the correspondent conditional hazard curve is determined by

$$
p\left(Z \geq z, \Delta t ; S T_{i}\right)=p\left(Z \geq z \mid S T_{i}\right) p\left(S T_{i}, \Delta t\right)
$$

If $p$ defines the probability of occurrence of at least one tsunami event, then $(1-p)$ is the generic probability that no tsunami occurs in the defined exposure time $\Delta t$. In this formalism, assuming their statistical independence, the product over the $N$ different types of tsunamigenic $S T_{i}$ represents the probability that none of the $S T$ s produces a value of the tsunami parameter $Z$ larger than the threshold $z$ in the time window $\Delta t$, 
so that the comprehensive PTHA for the $N$ tsunamigenic source types is deduced by

$$
p(Z \geq z, \Delta t)=1-\prod_{i=1}^{N}\left[1-p\left(Z \geq z, \Delta t ; S T_{i}\right)\right] .
$$

Each contribution to the total PTHA is evaluated separately by considering that the $i$ th source type $S T_{i}$ can be represented by a number $N_{i}(i=S S S, S M F, P D C)$ of independent physical source events $S E_{i j}$. The $S E_{i j}$ indicates the $j$ th source event of the $i$ th source type data set. In the seismic example, $S E_{i j}$ designates the $j$ th specific earthquake with a given location, size, and magnitude with $j \in\left[1, \ldots, N_{S S S}\right]$. As a consequence, the probability to generate a $Z \geq z$ for each independent tsunamigenic physical source event $j$ of type $i$ is expressed by

$$
p\left(Z \geq z, \Delta t ; S T_{i}\right)=1-\prod_{j=1}^{N_{i}}\left[1-p\left(Z \geq z, \Delta t ; S E_{i j}\right)\right] .
$$

Similarly to equation (2), in equation (3) the product over the $N_{i}$ types of tsunamigenic $S E_{i j}$ represents the probability that none of the source events produces a value of the tsunami parameter $Z$ larger than $z$ in $\Delta t$. The total number of all tsunamigenic source events $S E_{i j}$ (for $j \in\left[1, \ldots, N_{i}\right]$ ) belonging to all tsunamigenic source types $S T_{i}$ (for $i \in[1, \ldots, N]$ ) is simply equal to $\sum_{i=1}^{N} N_{i}$. This number corresponds to the number of tsunamigenic scenarios accounted in the probabilistic analysis.

Finally, the comprehensive PTHA is formulated in case of different types of sources by combining equations (2) and (3)

$$
p(Z \geq z, \Delta t)=1-\prod_{i=1}^{N} \prod_{j=1}^{N_{i}}\left[1-p\left(Z \geq z, \Delta t ; S E_{i j}\right)\right]
$$

with the following assumptions:

(a) the STs sizes are statistically independent;

(b) each $S E$ is assumed independent of the other source events within the same source type for all types of sources;

(c) the propagations of different tsunami waves are effectively independent also in the case of almost simultaneous events; and

(d) the PTHA is implicitly relative to the next main tsunami event and possible succeeding events are not included (similarly to PVHA, which does not encompass subsequent eruptions) because the factors characterizing the system (e.g., morphology of the coasts) may change when one significant tsunami event (or simply its source) occurs.

\subsection{Bayesian PTHA}

For simplicity, the generic $p(Z \geq z, \Delta t)$ is indicated by $P$ and the corresponding probability density distribution describing its epistemic uncertainty by $[P]$. Also, given a set $Y$ of the observed data $y$ the corresponding probability density distribution is indicated by $[Y]$. The Bayes' theorem updates $P$ in light of the observed data (Gelman et al., 2013; Grezio et al., 2015; Marzocchi et al., 2008):

$$
[P \mid Y]_{\text {post }}=\frac{[P]_{\text {prior }}[Y \mid P]_{\text {likel }}}{[Y]_{\text {data }}} .
$$

The posterior probability density distribution $[P \mid Y]_{\text {post }}$ combines the prior probability density distribution $[P]_{\text {prior }}$ and the likelihood $[Y \mid P]_{\text {likel }}$.

The prior probability density distribution $[P]_{\text {prior }}$ encodes our previous knowledge of the system and is the $p(Z \geq z, \Delta t)$ computed in equation (4).

The likelihood $[Y \mid P]_{l i k e l}$ indicates the probability of observing the data $y$ given the tsunami hazard model. Catalogs and/or historical records are examined to extract the past data $y$. The $[Y]_{\text {data }}$ is simply a constant normalization factor, which ensures that $[P \mid Y]_{\text {post }}$ integrates to 1 .

The Bayesian comprehensive PTHA for different types of sources is evaluated by the posterior probability density distribution in the application sites. 
In the Bayesian analysis we assume that the prior probability distribution $[P]_{\text {prior }}$ can be reasonably well approximated by an unimodal Beta function with hyperparameters $\alpha$ and $\beta$ :

$$
[P]_{\text {prior }}=\frac{1}{B(\alpha, \beta)} P^{\alpha-1}(1-P)^{\beta-1}, 0<P<1, \alpha>0, \beta>0,
$$

where the $B(\alpha, \beta)$ function is defined by the following integral:

$$
B(\alpha, \beta)=\int_{0}^{1} x^{\alpha-1}(1-x)^{\beta-1} d x, x \in[0,1] .
$$

The $\alpha$ and $\beta$ hyperparameters are determined by the average $E$ and the variance $V$ of the prior Beta distribution:

$$
E=\frac{\alpha}{\alpha+\beta}, V=\frac{E(1-E)}{\alpha+\beta+1} .
$$

The average $E$ is set by the hazard evaluated from all tsunamigenic scenarios. The variance $V$ is set by considering the reliability $\Lambda(=\alpha+\beta+1)$ of the statistical model that produces the prior probability distribution (Marzocchi et al., 2008; Grezio et al., 2012, 2010). For example, considering the methodological character of this paper, the definition of the sources is here largely imposed by reducing the computational effort; therefore, a very high epistemic uncertainty should be considered.

The occurrence or not of tsunamis in the time window $\Delta t$ is the random observation $\theta$ in a Binomial model $\operatorname{Bin}(n, \theta)$ formalized by the following Bernoulli schema:

$$
\operatorname{Bin}(n, \theta)=\left(\begin{array}{l}
n \\
y
\end{array}\right) \theta^{y}(1-\theta)^{(n-y)},
$$

where $y$ is the count of successes and $(n-y)$ are the failures. Indeed, the likelihood of the historical events is a Binomial distribution when tsunamis are counted as successful events occurred in the selected time windows. If $\Delta t$ is expressed in $n$ years, the $y$ past data are the years reported by the historical catalog with the tsunami parameter $Z$ overcoming the threshold levels $z$, and $(n-y)$ are the years when no tsunami occurred and/or overcame the thresholds. Then, the likelihood of $P$ is defined in the range $[0,1]$ by

$$
[Y \mid P]_{\text {likel }}=\operatorname{Bin}(n, P) .
$$

When the likelihood distribution follows a Binomial model with success $f u l$ and unsuccess $f$ ul events, some convenient statistical properties may be used. In this case, the prior Beta function in equation (6) is the conjugate distribution of the Binomial model in equation (10), and the posterior function results in another Beta function of the same family with hyperparameters $\alpha^{\prime}$ and $\beta^{\prime}$ (Gelman et al., 2013; Grezio et al., 2017; Marzocchi et al., 2008). This greatly simplifies any calculation because the posterior probability distribution $P \mid Y_{\text {post }}$ is represented by the modified $\operatorname{Beta}\left(\alpha^{\prime}, \beta^{\prime}\right)$ function where the past data define the hyperparameters $\alpha^{\prime}(=\alpha+y)$ and $\beta^{\prime}(=\beta+n-y)$. As a result, the posterior probability density distribution is updated by the historical information

$$
[P \mid Y]_{p o s t}=\frac{1}{B\left(\alpha^{\prime}, \beta^{\prime}\right)} P^{\alpha^{\prime}-1}(1-P)^{\beta^{\prime}-1}, 0<P<1, \alpha^{\prime}>0, \beta^{\prime}>0
$$

The $[P \mid Y]_{\text {post }}$ in equation (11) provides the reformulated probability density distribution of the epistemic uncertainty on $p(Z \geq z, \Delta t)$, which is finally used to produce the hazard curves and the hazard maps for the long-term multisource Bayesian PTHA. In the posterior analysis the epistemic uncertainty is reduced when more historical information becomes available because the equivalent number of data $\Lambda^{\prime}(=\Lambda+n)$ increases and proportionally the variance decreases.

\section{Modeling Potential Tsunamigenic Sources and Tsunami Waves}

The potential tsunamigenic sources ( $S S S \mathrm{~s}, S M F$ s and $P D C$ s) are identified in the region (Figure 2) to produce the corresponding tsunami scenarios for the PTHA. The procedure introduced by Grezio et al. (2010) is implemented through the following modules: 


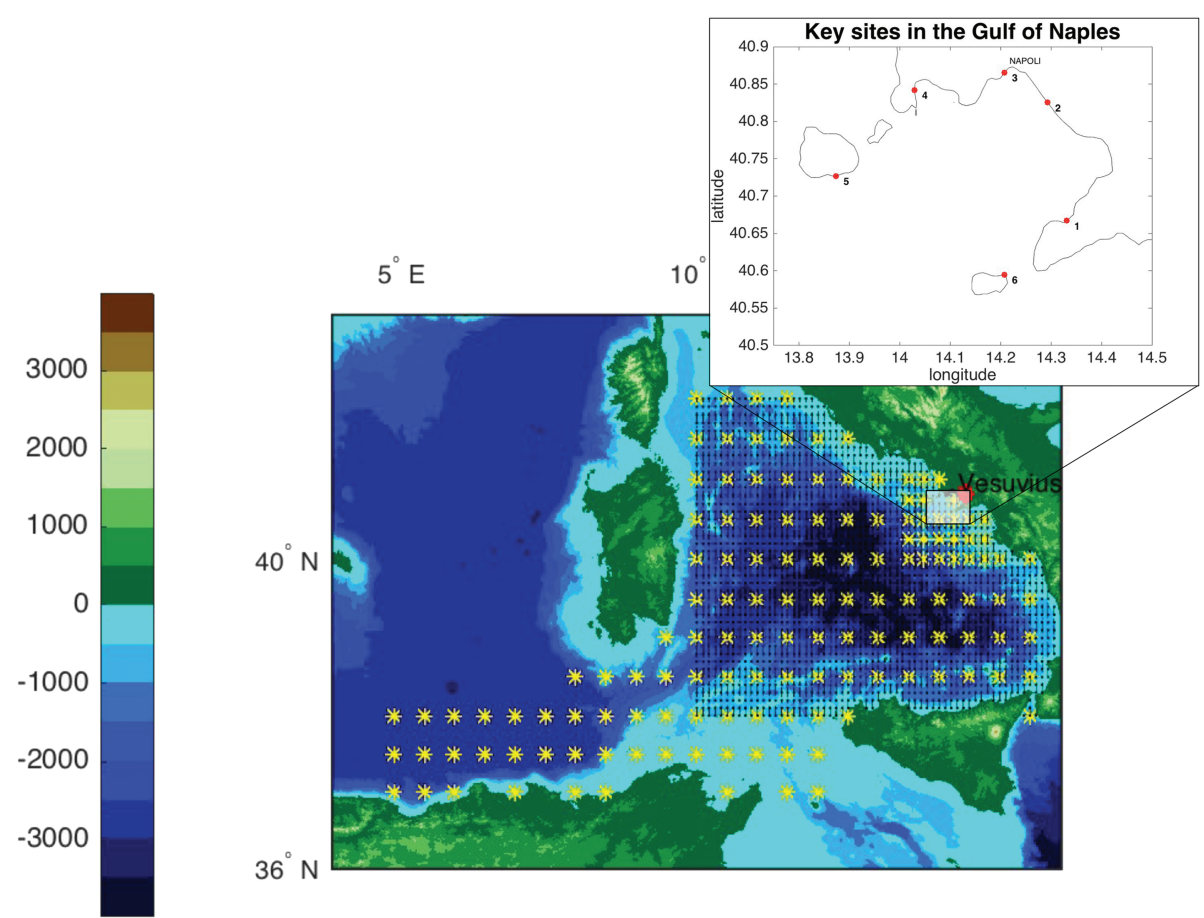

Figure 2. The tsunamigenic sources for the PTHA at selected sites in the Gulf of Naples. The submarine seismic sources $(S S S s)$ are localized on a coarse grid $\left(0.5^{\circ} \times 0.5^{\circ}\right)$ used in the North-African Mediterranean Sea and in the Tyrrhenian Sea and on a finest grid $\left(0.25^{\circ} \times 0.25^{\circ}\right)$ in the area of the Gulf of Naples. The submarine mass failures $(S M F \mathrm{~s})$ are located in the Tyrrhenian Sea and spaced on a regular grid at higher spatial resolution $\left(1^{\prime} \times 1^{\prime}\right)$. The pyroclastic density currents (PDCs) come from Somma-Vesuvius, near the city of Naples. The enlarged square shows the sites in the Gulf of Naples where the PTHA is evaluated. The number labels correspond to the following localities: Sorrento (1), Torre del Greco (2), Napoli (3), Baia (4), Ischia Sud (5), and Capri Nord (6).

1. Source Module: The source events are spatially localized, and the relative magnitudes and characteristic parameters are defined to set the initial tsunami waves.

2. Wave Module: The initial tsunami waves are computed and propagated by a shallow water numerical model.

3. Impact Module: The tsunami wave amplitudes at the selected coastal sites are estimated using an amplification law of the wave amplitudes at the isoline of $50 \mathrm{~m}$ depth.

\subsection{Source Module}

The tsunami generation phase defines large data sets of potential tsunamigenic events for the different types of sources. These data set are assumed to be sufficiently representative of the natural variability (aleatory uncertainty) of each source. Tsunamigenic sources may be very different in size, location, and occurrence even if they belong to the same specific source type. Considering that our study illustrates an analysis of the multisource Bayesian PTHA, the definition of the sources is here simplified to reduce the computational effort. The hazard assessment in the Campania region would require a much larger data sets to cover effectively the natural variability.

\subsubsection{Submarine Seismic Sources}

Source locations. A large number of tsunamigenic seismic events has to be planned despite the scarce information on the submarine earthquake locations and faults in the region. For this reason a gridded domain is implemented. In other words, the localization of the epicenters is on a grid with predefined latitudes and longitudes, and the hypocenters occurs at predefined depths. This approach allows the following:

a) evaluation of the far and near tsunamigenic sources;

b) the limited time coverage of the instrumental database.

In the Tyrrhenian Sea and in the North-African area, the epicentral locations are spaced on a $0.5^{\circ} \times 0.5^{\circ}$ grid and are indicated as the far sources. In the Gulf of Naples the seismic sources are on a finest grid of $0.25^{\circ} \times 0.25^{\circ}$ and defined as the near sources. 


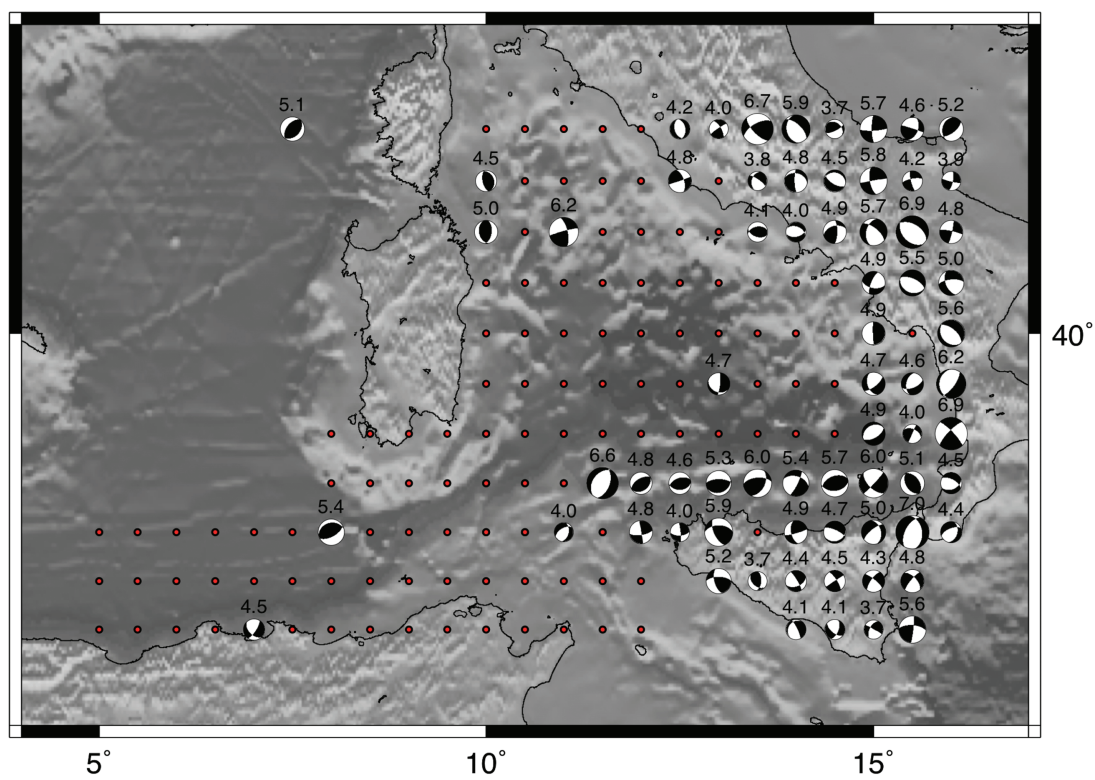

Figure 3. Cumulative moment tensors for the central Mediterranean Sea. Each cumulative moment tensor is located in the center of the grid element used for summation. On their top the cumulative $M_{w}$ is reported. Where no data are available, the grid is still represented by red dots.

Magnitude classes. The source events are grouped in four classes of 0.5 magnitudes spanning the interval of moment magnitude [6.0-8.0]. The lower and upper limits in the Tyrrhenian region are chosen considering the background seismotectonics. They represent, respectively, the minimum magnitude for the generation of a tsunami wave and the lack of evidence of earthquakes larger than 8.0 in the last millennia.

Fault dimensions. The length, width, and slip parameters scale the geometry of the fault. For each representative magnitude of the four classes, the fault parameters are calculated by empirical relationships (Wells \& Coppersmith, 1994). In order to introduce a certain variability and enlarge the statistical data set of the source events, the fault parameters were randomly sampled twice in the interval provided by Wells and Coppersmith (1994).

Fault geometry. The orientation angles (strike, dip, and rake) are predetermined for each grid element from cumulative moment tensors. The cumulative moment tensors are obtained with a summation of source parameters of earthquakes occurred in the grid element in the last 100 years. This time span guarantees that the cumulative moment tensors are representative of the tectonic style of future earthquakes (Figure 3). In practice, seismic moment tensors have been extracted from available catalogs and database (RCMT Catalog doi:10.13127/rcmt/euromed, Pondrelli \& Salimbeni, 2015; Italydataset doi:10.13127/rcmt/italy, Pondrelli et al., 2006; EMMA https://www.emsc-csem. org/Earthquake/emma.php, Vannucci \& Gasperini, 2004) for shallow earthquakes $(D<50$ $\mathrm{km}$ ) with a magnitude greater than 4.0 occurred in the study region. All gathered data have summed on the regular grid already described, following Kostrov and Das (1988) and several similar previous applications (Serpelloni et al., 2007). The results, shown in Figure 3, are given by a focal mechanism for each element of the grid (where data were available), which we assume as representative of the tectonic style of future seismic events. This choice is a simplification that reduces the number of simulations and limits the data set to a number of cases sufficient for the analysis. For a complete hazard assessment a better exploration of the natural variability of the focal mechanisms in each location was presented by Selva et al. (2016).

\subsubsection{Submarine Mass Failures}

Source Identification. The limited amount of available specific slide data requires the gridding of the Tyrrhenian Sea domain. The cell dimensions are $1^{\prime}$ according to the lengths of the known 


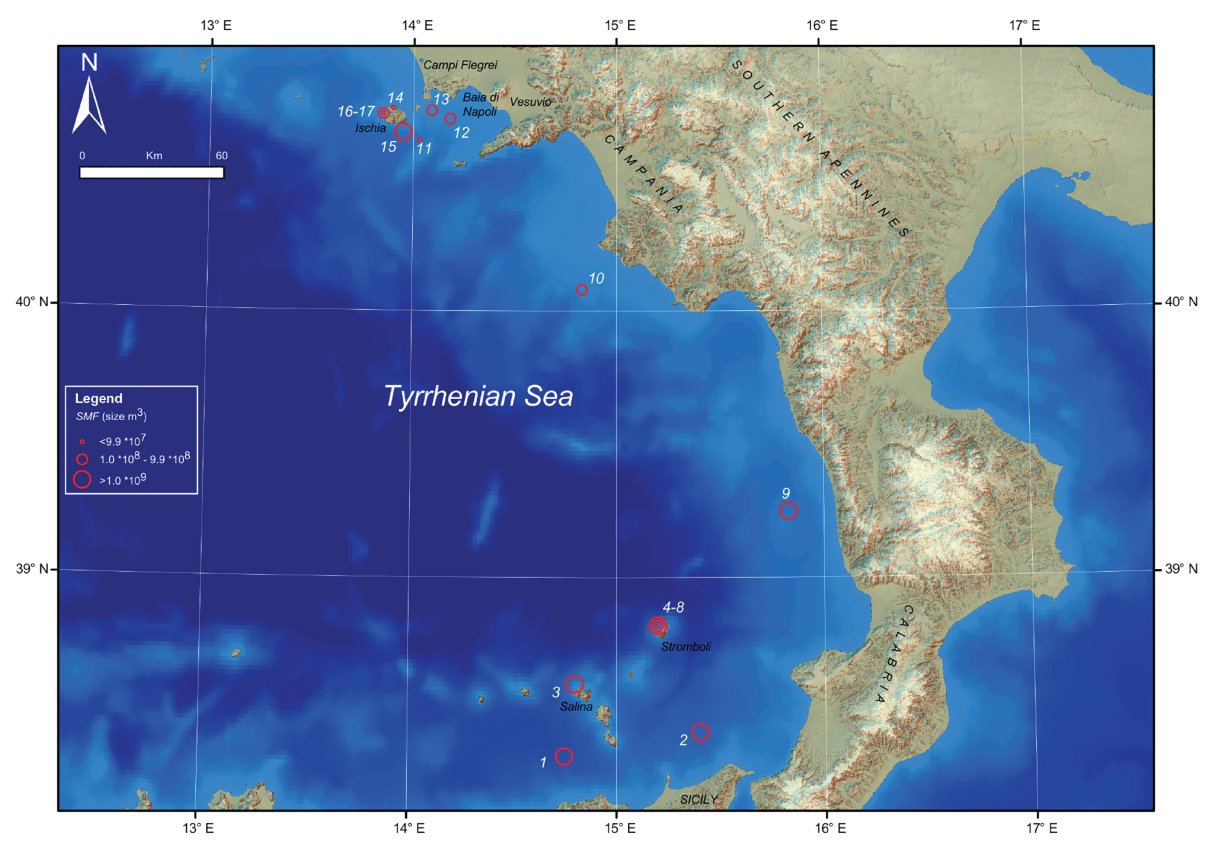

Figure 4. Past submarine slides in the Tyrrhenian Sea. The Id is provided in Table 1.

past slides (Figure 4). Each cell provides a potential SMF and is adequately weighted in section 4.1.2.

Mass volume classes. Volumes of the mass failures are grouped in five classes in the range $\left[5 \times 10^{5}-5 \times\right.$ $10^{10} \mathrm{~J} \mathrm{~m}^{3}$ and are associated to each cell. The classes are chosen on the basis of the past regional events (de Alteriis et al., 2010; Della Seta et al., 2012; Grezio et al., 2012; Milia et al., 2006) (Table 1). The paucity of information regarding small submarine mass failures imposes the use of alternative indications on the classes considering the

Table 1

Subaerial and Submarine Mass Failures Documented in the Tyrrhenian Region

\begin{tabular}{|c|c|c|c|c|c|c|}
\hline Id & Latitude & Longitude & Size $m^{3}$ & $N$. of events & Site Name & Time, years before present $\left({ }^{*}\right.$ is present time) \\
\hline 1 & 38.333333 & 14.75 & $6.4 \times 10^{9}$ & 1 & Capo d'Orlando ${ }^{\mathrm{a}}$ & 10,000 \\
\hline 2 & 38.416667 & 15.4 & $5.4 \times 10^{9}$ & 1 & Villafranca $^{\mathrm{a}}$ & 10,000 \\
\hline 3 & 38.6 & 14.8 & $3.0 \times 10^{9}$ & 1 & Salina $^{\mathrm{b}}$ & 10,000 \\
\hline 4 & 38.816667 & 15.2 & $9.6 \times 10^{6}$ & 5 & Stromboli $^{\mathrm{c}}$ & in $2002^{*}$ \\
\hline 5 & 38.816667 & 15.2 & $7.3 \times 10^{8}$ & 5 & Stromboli $^{\mathrm{d}}$ & 5,000 \\
\hline 6 & 38.816667 & 15.2 & $1.1 \times 10^{9}$ & 5 & Stromboli $^{\mathrm{a}}$ & 5,000 \\
\hline 7 & 38.816667 & 15.2 & $1.0 \times 10^{9}$ & 5 & Stromboli $^{\mathrm{a}}$ & 5,000 \\
\hline 8 & 38.816667 & 15.2 & $2.23 \times 10^{9}$ & 5 & Stromboli ${ }^{\mathrm{a}}$ & 13,000 \\
\hline 9 & 39.25 & 15.83333 & $5.0 \times 10^{9}$ & 1 & Bacino di Paola $^{a}$ & 14,000 \\
\hline 10 & 40.083333 & 14.83333 & $3.2 \times 10^{8}$ & 1 & Capo Licosa ${ }^{\mathrm{a}}$ & 14,000 \\
\hline 11 & 40.642279 & 14.030219 & $3.8 \times 10^{6}$ & 1 & Baia Napoli (GB, Gaia Bank) ${ }^{\mathrm{b}}$ & $15,000-6000$ \\
\hline 12 & 40.715531 & 14.183070 & $100 \times 10^{6}$ & 1 & Baia Napoli (DC, Dohrn Canion) ${ }^{b}$ & $15,000-6000$ \\
\hline 13 & 40.748646 & 14.093825 & $200 \times 10^{6}$ & 1 & Baia Napoli (MB, Miseno Bank) ${ }^{\mathrm{b}}$ & $15,000-6000$ \\
\hline 14 & 40.758261 & 13.904143 & $15-20 \times 10^{6}$ & 1 & Ischia Nord $^{c}$ & $3,000-2,400$ \\
\hline 15 & 40.668576 & 13.947021 & $1.5 \times 10^{9}$ & 1 & Ischia Sud & 23,000 \\
\hline 16 & 40.735166 & 13.845308 & $80-150 \times 10^{6}$ & 1 & Ischia West ${ }^{\mathrm{c}, \mathrm{d}}$ & 5,500 \\
\hline 17 & 40.735459 & 13.874910 & $1 \times 10^{6}$ & 1 & Ischia West ${ }^{\mathrm{c}, \mathrm{d}}$ & 5,500 \\
\hline
\end{tabular}

Note. Id refers to the numbers of Figure 4.

${ }^{\mathrm{a}}$ Grezio et al. (2012). ${ }^{\mathrm{b}}$ Milia et al. (2006). ${ }^{\mathrm{c}}$ de Alteriis et al. (2010). ${ }^{\mathrm{d}}$ Della Seta et al. (2012). 
subaerial known events in the region. As a consequence, the lower class is set according to a known subaerial mass failure occurred at the Stromboli volcano in December 2002 and estimated about $5 \times 10^{5} \mathrm{~m}^{3}$ by Calvari et al. (2005). The upper class represents the sizes of the largest historical slides occurred in the Tyrrhenian Sea (e.g., Fabbri et al., 1981). The resulting classification is surely very rough but could be deeply revised in the future.

Geometric parameters. A simplified geometric shape describes the mass failures (Watts et al., 2005). The relative parameters (length, thickness, and width of rigid block) are deduced by volumes of class sizes using basic assumptions. SMFs moving over plane slopes can be schematized in two idealized types: translational failures, which are underwater slides, and rotational failures, which are slumps. They generally represent end-members of a wide range of possible $S M F$ motions. Commonly, for an initial slide length $l_{\text {slide }}$, the slide width is $0.25 \times l_{\text {slide }}$, and the slide thickness is $0.01 \times l_{\text {slide }}$; for an initial slump length $l_{\text {slump }}$ the related slide width is almost equivalent to the $l_{\text {slump }}$, and the slump thickness is $0.1 \times l_{\text {slump }}$ (Watts et al., 2005). As for volume classes, also, this rather rough parametrization could be deeply revised in the future (e.g., Kim et al., 2019; Løvholt et al., 2005, 2015; Løvholt \& Urgeles, 2017, 2005; Ward, 2001).

3.1.3. Pyroclastic Density Currents

Somma-Vesuvio.We only consider the dense PDCs of Somma-Vesuvio as a volcanic source for tsunamis because we have historical evidence of tsunamigenesis due to dense PDCs entering the sea (Tinti et al., 2004). The expected frequency of dense PDCs from an eruption of any size from Somma-Vesuvio summit is deduced by Sandri et al. (2018).

Eruptive size classes. We rely on a set of TITAN2D (Patra et al., 2005) simulations for dense PDCs from the summit crater of Somma-Vesuvio, performed by Tierz et al. (2018) considering a wide range of possible eruptive size classes (small, medium, and large) that ultimately reflect different total erupted masses (see also Sandri et al., 2016). We have available 64 simulations for each size class. In each simulation, we account for a volume and bed-friction angle of the generated dense $P D C$ s, which are coherent with the natural variability of the specific eruptive size class. The density of $P D C$ s is generically set at a value of $1,250 \mathrm{~kg} / \mathrm{m}^{3}$ (Sulpizio et al., 2007). We note that for the small size class, no simulated $P D C$ s make it to the sea, while for the mediumand large-size class, some $P D C$ simulations reach the coast with the minimum tsunamigenic thickness. For a given size class, we retrieve only the simulations in which $P D C$ s reach the coast and potentially generate tsunami waves.

Flow parameter. The flow thicknesses simulated by TITAN2D at the coastal points are considered the key input parameters for the subsequent modeling of the potential initial tsunami waves. Only thickness of the pyroclastic flow $\geq 1 \mathrm{~m}$ at the coastal points is estimated relevant to enter into the sea and generate tsunami waves in the Gulf of Naples.

\subsection{Wave Module}

The initial tsunami waves are generated by the seafloor (SSSs and SMFs), and sea surface deformations $(P D C s)$ caused by tsunamigenic sources are described in the previous subsections. Then the tsunami waves are propagated near the coast by a tsunami numerical model based on the shallow water equations (SWEs). The Cornell Multi-grid Coupled Tsunami Model (COMCOT) (Liu et al., 1994, 1995; Wang \& Liu, 2005, 2006) is capable of generating and propagating tsunamis and has been widely used for tsunami simulations (by Megawati et al., 2009, in Manila Trench South China Sea megathrust; by Syamsidik et al., 2015, in the Indian Ocean; by Barkan et al., 2009, in the Atlantic Ocean for the far field 1755 Lisbon earthquake; by Wang \& Liu, 2005, in the Mediterranean Sea; and by Ichihara et al., 2013, for the Tohoku Earthquake and Tsunami). Even if more recent and updated numerical codes exist (e.g., González-Vida et al., 2019; Løvholt et al., 2017; Macías et al., 2016), the COMCOT model fits ours needs, for the possibility of homogeneously covering all the considered sources, as well as for its relatively easy implementation and its availability online. The COMCOT model is able to simulate tsunami waves with an explicit leap-frog finite difference scheme and multisize nested grids. The free surface elevation and the volume flux are staggered both in time and in space. The model runs in two modes. In a shallow water mode COMCOT resolves the Boussinesq SWEs in spherical coordinates. However, when the tsunami waves propagate from offshore to near-shore areas, the nonlinear effects increase significantly, and the linear SWEs became not appropriated. For this reason the COMCOT provides an alternative mode that resolves the weakly nonlinear SWEs in spherical coordinates. 


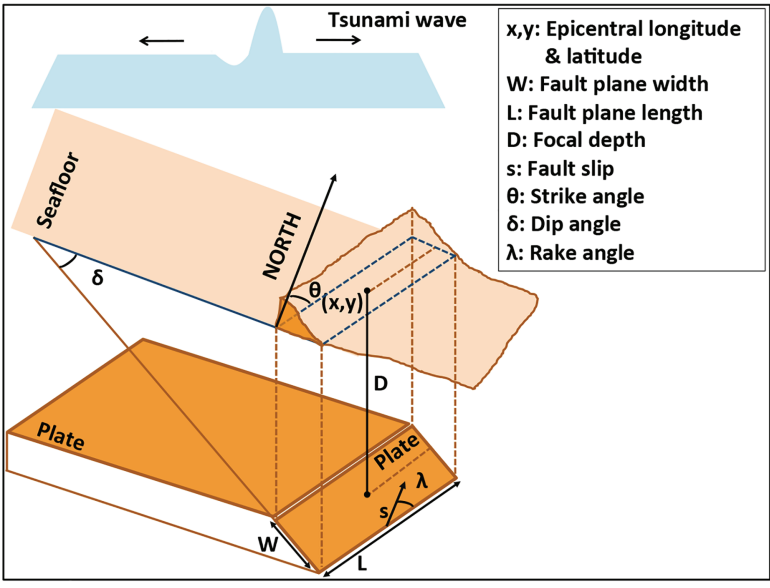

a)

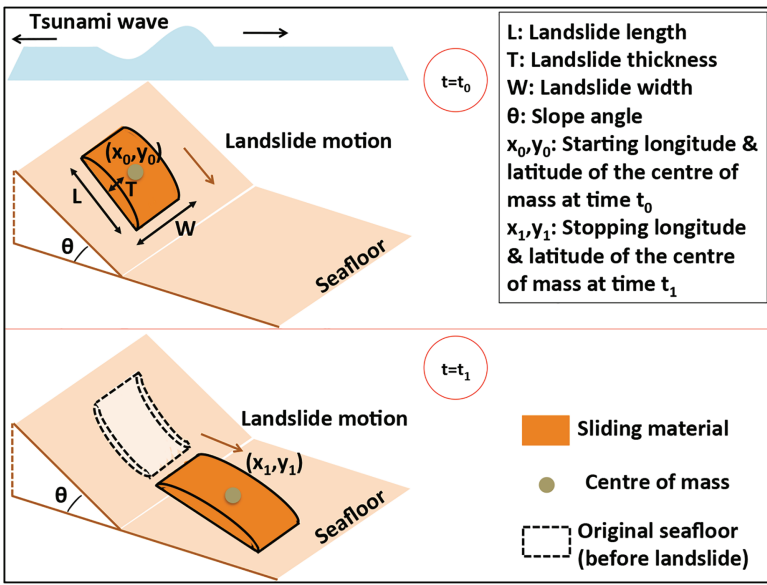

b)

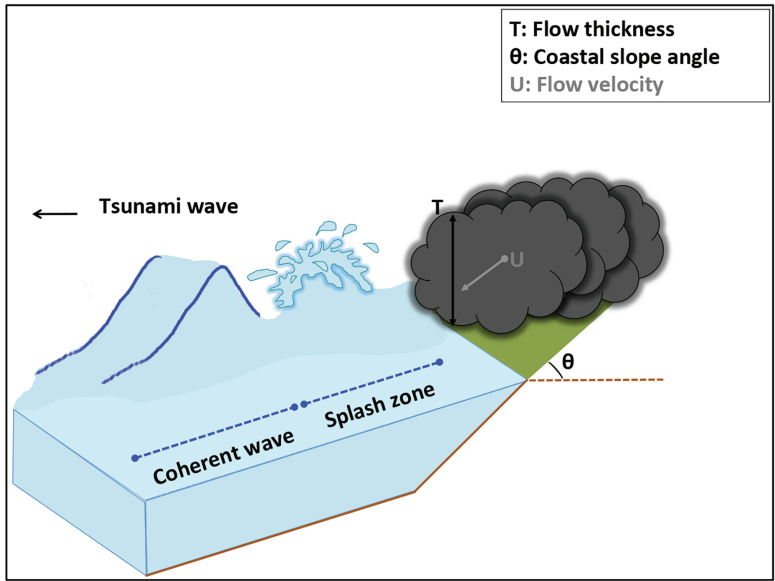

c)

Figure 5. Source parameters characterizing the (a) SSSs, (b) SMFs, and (c) PDCs.

The bottom shear stress is computed by the Manning's formula and the settings of the Manning's roughness coefficient. The SWEs are adequate to describe tsunami waves without including dispersion because physical frequency dispersion effects can be neglected when wavelength scales are much larger than water depth. When tsunamis approach the coast, the dispersion effects cannot be neglected anymore. In the COMCOT model the physical dispersion can be partially recovered by choosing grid size $d x$ and time step $d t$ according to the following relationship:

$$
d x=\left(\left(4 h^{2}+g h(d t)^{2}\right)\right)^{1 / 2}
$$

This means the tsunamis are weakly nonlinear and weakly dispersive waves over a slowly varying bathymetry. 


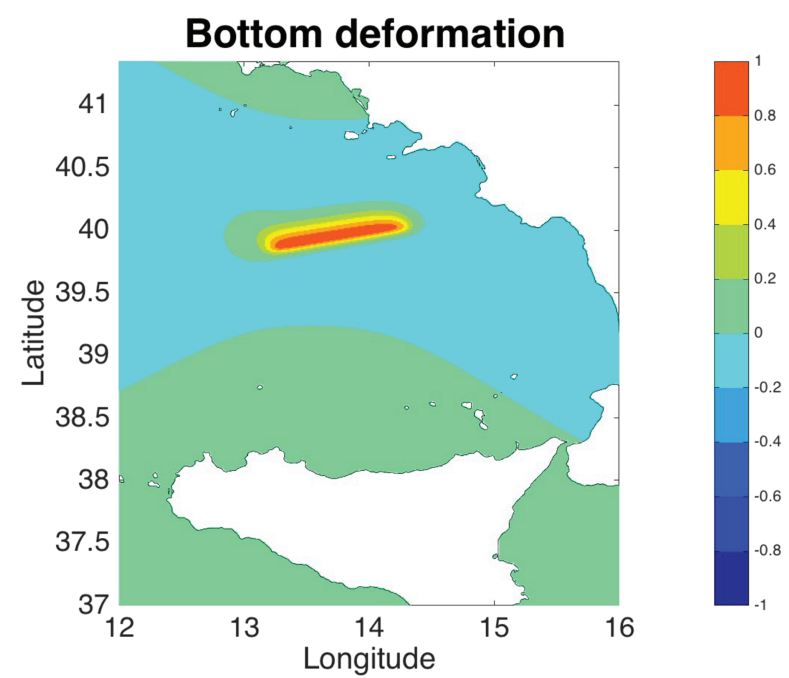

a)

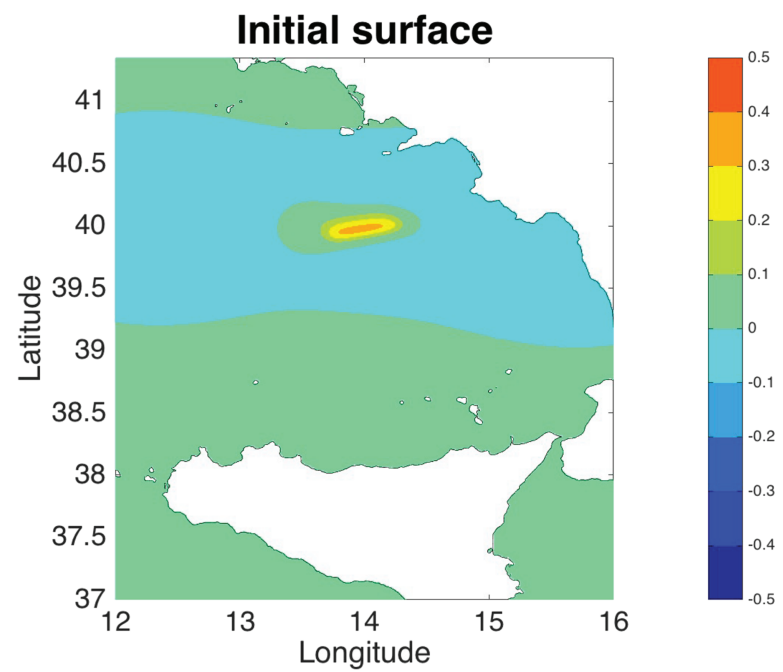

b)

Figure 6. Example of the (a) bottom deformation and (b) initial surface wave caused by a SSS (scenario number 585 of the $S S S$ data set).

\subsubsection{Initial Waves}

In the $S S S$ case, the COMCOT model computes the seafloor deformation imparted by the fault parameters (latitude and longitude of the epicenter, focal depth, length and width of the fault plane, fault slip, strike, dip, and rake angles) described in section 3.1.1 and schematized in Figure 5a. Those earthquake parameters characterize the seafloor disturbance that corresponds to the initial tsunami wave (an example is shown in Figures $6 \mathrm{a}$ and $6 \mathrm{~b}$ ) to be propagated near the coast. The model assumes a rectangular fault in a semi-infinite elastic half plane with an idealized representation of the interface between two colliding crustal blocks during the earthquake event. The relative motion of the blocks is simulated as an instant seafloor deformation neglecting the duration of the rupturing process (Mansinha \& Symlie, 1971; Okada, 1985).

In the $S M F$ case the initial tsunami waves are computed by the numerical model, similarly to the seismic case. The COMCOT model sets the seafloor deformation both by the slide parameters (starting and stopping coordinates of the center of mass, typical slope angle along the sliding path, length, width, and thickness of the sliding volume) deduced by section 3.2.2 and by the duration of the transient seafloor motion (time of the temporal variation of the water depth) (Figure $5 b$ ). The longwave assumption is satisfied in the numerical model implementation (Wang \& Liu, 2006).

In the $P D C$ s case, a different procedure is implemented because the 3-D initial tsunami waves are assigned as sea surface disturbances in the COMCOT model. These disturbances are previously computed by the numerical model SPHysics based on the Smoothed Particle Hydrodynamics theory (Monaghan, 2005). In 
Table 2

COMCOT Model Setting

SSS

Use built-in fault model (see Okada, 1985 model)

Total number of fault segments : 1

Fault rupture time (second): 0.0

Epicenter (longitude, latitude) (degree): See Source Locations in section 3.1.1

Focal depth (km): See Source Locations in section 3.1.1

Fault length (km): See Fault dimensions in section 3.1.1

Fault width (km): See Fault dimensions in section 3.1.1

Fault slip (m): See Fault dimensions in section 3.1.1

Strike angle ( $\theta$, degree): See Fault geometry in section 3.1.1

Dip angle ( $\delta$, degree): See Fault geometry in section 3.1.1

Rake angle ( $\lambda$, degree): See Fault geometry in section 3.1.1

Grid size ( $d x$, minute): 0.5

Grid size ( $d y$, minute): 0.5

Time step size ( $d t$, second): 1.0

Bathymetry data file name: GEBCO30arc - sec

Shoreline located at depth contour: 0.0

Spherical coordinate system: used

Bottom friction: enabled

Constant roughness coef.: $1.3 \times 10^{-2}$

Number of child grid layers: 0

$S M F$

Use submarine landslide model (see function in Watts et al., 2003)

Landslide starting time (second): 0.0

Landslide duration (second) : 600.0

Landslide starts at $\left(x_{0}, y_{0}\right)$ : See Source Identifications in section 3.1.2

Landslide stops at $\left(x_{1}, y_{1}\right)$ : deduced by both Mass volume classes and Geometric Parameters in section 3.1.2

Typical slope of path (degree): deduced by the Bathymetry

Length of sliding mass $(m)$ : deduced by both Mass volume classes and Geometric Parameters in section 3.1.2

Width of sliding mass $(m)$ : deduced by both Mass volume classes and Geometric Parameters in section 3.1.2

Thickness of sliding mass $(m)$ : deduced by both Mass volume classes and Geometric Parameters in section 3.1.2

Grid size ( $d x$, minute): 0.5

Grid size ( $d y$, minute): 0.5

Time step size ( $d t$, second): 1.0

Bathymetry data file name: GEBCO30arc - sec

Shoreline located at depth contour: 0.0

Spherical coordinate system: used

Bottom friction: enabled

Constant roughness coef. : $1.3 \times 10^{-2}$

Number of child grid layers: 0 
Table 2

Continued

PDC

Use initial surface deformation file: from the SPHysics and TITAN2D models in section 3.1.3

Grid size ( $d x$, minute): $2.3772 \times 10^{-2}$

Grid size ( $d y$, minute): $2.3772 \times 10^{-2}$

Time step size ( $d t$, second): $7.49 \times 10^{-2}$

Bathymetry data file name: bathy $50 \mathrm{~m}$

Shoreline located at depth contour: 0.0

Spherical coordinate system: used

Bottom friction: enabled

Constant roughness coef.: $1.3 \times 10^{-2}$

Number of child grid layers: 0

the setup of the SPHysics model the PDCs entering the sea (which were calculated by Tierz et al., 2018) correspond to the case of tsunamis generated by sliding wedge. For each scenarios the wedge is equal to the pyroclastic flow thickness $\geq 1 \mathrm{~m}$ at the coastal point, the slope is fixed at the average coastal slope, and the specific weight is a background value related to a generic PDCs density. The SPHysics model setting does not include the flow velocity as key parameter. Simulating the impact velocity of the $P D C$ s could improve the modeling of the initial tsunami waves and could reduce the epistemic uncertainties related to the initial tsunami waves. During a transient time, each sliding wedge moves the sea water particles producing surface local peaks. Finally, a waveform is extracted by the use of smoothing routines, which trace the 2-D initial tsunami wave entering the sea. Width of pyroclastic flow is the along coast parameter that sets the 3-D initial sea surface disturbance to be propagated by the COMCOT model (Figure 5c).

3.2.2. Wave Propagation

All initial tsunami waves are propagated in the Tyrrhenian Sea using the spherical coordinate system of the COMCOT model in consideration of the latitudinal extension of the simulation domain. The bathymetry is the General Bathymetric Chart of the Oceans (GEBCO) with a 30 arc second intervals of latitude and longitude for ocean and land (https://www.gebco.net/data\&urluscore;and\&urluscore;products/gridded\& urluscore;bathymetry\&urluscore;data/) for the SSS and SMF simulations. A reduced domain and a higher bathymetry resolution of grid size of about $50 \mathrm{~m}$ are used for the $P D C$ simulations.

The resolution of the domain allows the use of (a) the first level model grid, without the sublevel grids, and (b) the nonlinear shallow water mode, with the Manning's roughness coefficient set equal to 0.013 (as in Power et al., 2014). This model setting provides the further advantage to reach a good compromise between the computer running time and the number of simulations needed for the statistical analysis. Table 2 summarize the COMCOT setting scenarios. The grid resolution and the time step reduce partially the physical dispersion discussed in equation (12). Figure 7 shows the maximum elevations of the tsunami waves in three example simulations for the SSSs, SMFs, and PDCs cases. Similar maps can be produced for all scenarios by varying the source parameters according to section 3.1 in the model setting (Table 2).

\subsection{Impact Module}

The impact of the tsunami waves is evaluated in terms of wave amplitude near the coast using the Green's law (Ippen \& Kulin, 1954). This empirical relationship assumes the wave front is almost parallel to the coastline where the wave refraction is toward the directions of the down-gradient depth and the convergence and/or divergence of the rays is neglected. With this assumption the wave amplitude variability due to the wave refraction is considered a second-order problem in the probabilistic analysis. Also, this energy conservation law estimates the evolution of the initial tsunami wave at the coastal line from an appropriate isoline where the nonlinearities are negligible.

The tsunami amplification at the coastal points is evaluated from the maximum water surface elevation at the isoline of $50 \mathrm{~m}$ depth by

$$
h_{0}=\sqrt[4]{\frac{d_{i s o}}{d_{0}}} h_{i s o}
$$




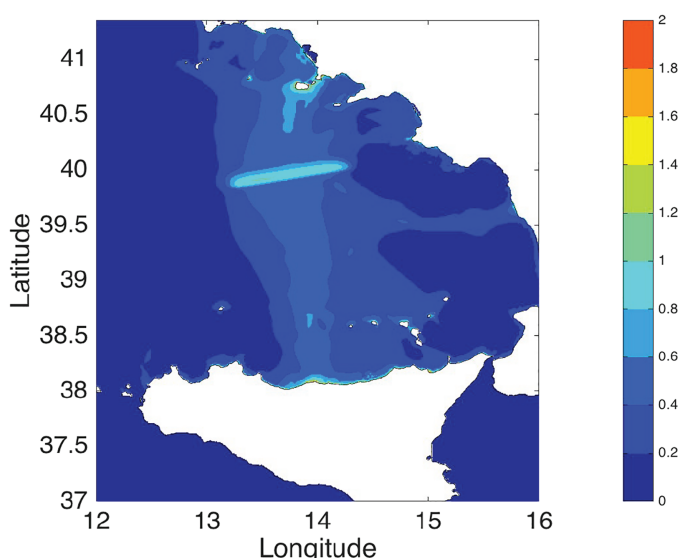

a)

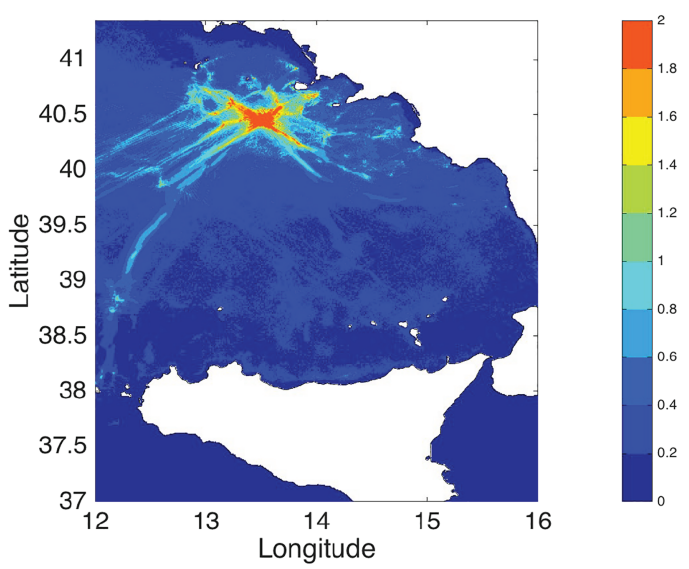

b)

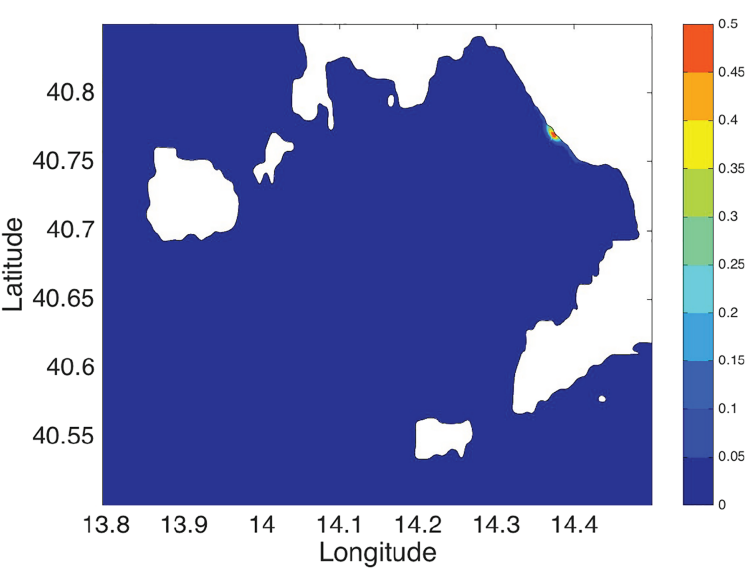

c)

Figure 7. Examples of maximum elevations of the tsunami waves for (a) SSS (scenario number 667), (b) SMF (scenario number 196) and (c) PDC (scenario number 286).

In the formula $h$ and $d$ are, respectively, the tsunami amplitude and the sea depth (Figure 8). The subscripts iso and 0 indicate, respectively, the $50 \mathrm{~m}$ depth isoline and the coastline. The tsunami amplitude at the coastal point is assumed to approximate the amplitude at $1 \mathrm{~m}$ depth $\left(h_{0} \approx h_{1}\right)$ to avoid singularities (Kamigaichi, 2009). In the probabilistic analysis the $h_{0}$ values are used to estimate the tsunami parameter $Z$ overcoming the thresholds levels $z(z \in[0.1 \mathrm{~m}, 0.2 \mathrm{~m}, \ldots, 1 \mathrm{~m}, \ldots, 5 \mathrm{~m}])$ at the coastal sites of the Gulf of Naples (Figure 8). Here we selected the simplest method, which is uniformly applied to all tsunami sources, instead of adopting more sophisticated amplification models that account for more specific coastal characteristics and estimate also the uncertainty (Glimsdal et al., 2019). Also, we note that for local hazard quantifications 


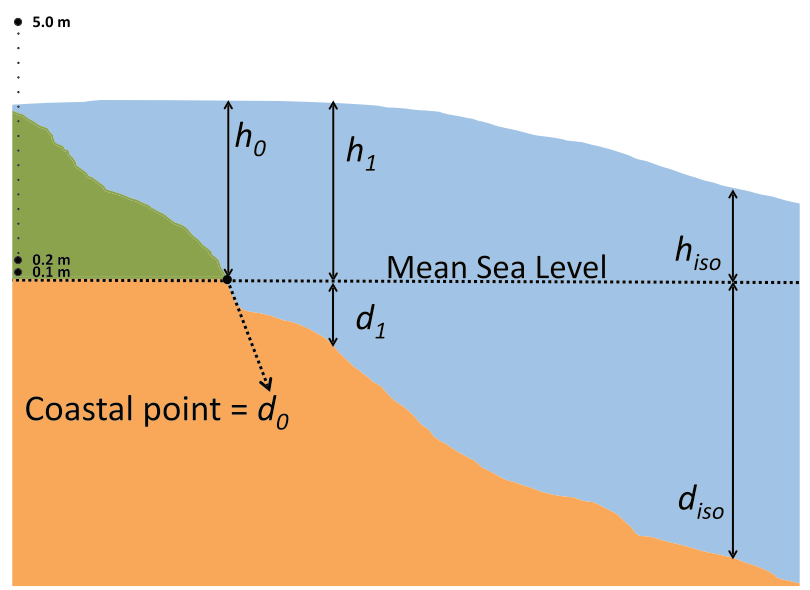

Figure 8. Representation of the Green's law and the threshold levels at the coastal points (not in scale). it would be preferable to consider simulations including inundation eventually coupled with strategies to reduce the computational effort (Lorito et al., 2015; Volpe et al., 2019).

\section{Multisource Bayesian PTHA}

\subsection{Prior Module: PTHA for Different Source Types}

The multisource PTHA is evaluated by combining the noninteractive probabilities and conditional probabilities estimated separately in the $P T H A_{S S S}, P T H A_{S M F}$ and $P T H A_{P D C}$.

The source probabilities are simply indicated by $P_{i j}$ and represent probabilities related to the parameters of the system. These source probabilities take into account the seismotectonics and the geologic characteristics of the region and are computed through three independent probability factors: temporal $\left(P_{i j}^{\text {temp }}\right)$, spatial $\left(P_{i j}^{\text {spat }}\right)$, and frequency size $\left(P_{i j}^{f r e q-s i z e}\right)$. They are examined for each source event $S E_{i j}$ (for $j \in\left[1, \ldots, N_{S S S}\right], j \in$ $\left[1, \ldots, N_{S M F}\right]$ and $\left.j \in\left[1, \ldots, N_{P D C}\right]\right)$ belonging to the different source types $S T_{i}(i=S S S, S M F, P D C)$. In order to cover all possible sources and reduce the number of simulations, an event tree strategy is implemented for the $S T_{S S S}, S T_{S M F}$, and $S T_{P D C}$.

The conditional probabilities are computed for the different threshold levels $z \in[0.1 \mathrm{~m}, 0.2 \mathrm{~m}, \ldots, 1$ $\mathrm{m}, \ldots, 5 \mathrm{~m}]$ at the coastal sites for each tsunami scenario, whose intensity is evaluated as described in sections 3.2 and 3.3. Following Selva and Sandri (2013), the probabilities to overcome the thresholds $z$ are not assumed independent. In fact, the probability $P_{i j}^{z_{l}}$ is necessarily smaller than or equal to the probability $P_{i j}^{z_{m}}$ if $z_{l} \geq z_{m}$, where $z_{l}$ and $z_{m}$ are generic levels in the threshold range. Here, as in Selva et al. (2016), we assume no uncertainty in the propagation (section 3.3). Thus, the conditional hazard curves are quantified as stepwise functions $p(Z>z)=\sum\left(H\left(h_{0}-Z\right) / N\right)$, where $H$ is the Heaviside function and $h_{0}$ the tsunami parameter intensity.

\subsection{1. $P T H A_{S S S}$}

The event tree implemented for the SSSs is modified from Lorito et al. (2015) and Selva et al. (2016) with the following nodes:

Node 1: event occurrence in the grid location. The probability of occurrence is associated to each grid center of the Tyrrhenian Sea and North-African Mediterranean Sea. It is the probability calculated using the Poisson occurrence $1-e^{-\lambda_{S S S} \Delta t}$, where $\lambda_{S S S}$ is the mean annual rate of occurrence of the SSSs in each grid center and $\Delta t$ is the exposure window. The mean annual rate is calculated as the number of events in each cell of Figure 2 in the time and magnitude of completeness based on the historical data of the European-Mediterranean Earthquake Catalogue (EMEC) for the last millennium (Grünthal et al., 2012). The completeness of the area is calculated separately for the Southern Italy and the Northern Algeria and Tunisia for historical reasons. The analysis of the cumulative number of earthquakes and the Gutenberg-Richter law (Gutenberg \& Richter, 1944) leads the definition of the time-magnitude of completeness of $M_{w} \geq 5.0$ since 1650 and 1900 for Southern Italy and Northern Algeria and Tunisia respectively (see Figure 9). The rates of the two areas are calculated separately as the number of events per exposure interval within the time-magnitude window of completeness. The spatial distribution of the simulated events follows a Gaussian filter with correlation distance equal to $20 \mathrm{~km}$ of the location of the real paste earthquakes in the area (Frankel, 1995). For the cells that have no events in the windows of completeness, we have arbitrarily associated a probability value of 1 order of magnitude smaller than the smallest values calculated.

Node 2:magnitude. The large earthquakes are less likely to occur compared to the events of smaller magnitude, so that each class of the SSSs is weighted using the frequency-size relation (Gutenberg \& Richter, 1944). The truncated Gutenberg-Richter distributions are determined by the $b$ values for both near sources (in the Tyrrhenian Sea) and far sources (in the North-African Mediterranean Sea). The evaluations of the $b$ values are based on the historical data of the EMEC for the last millennium (Grünthal et al., 2012). The $b$ value of the Gutenberg-Richter relation is estimated as $0.96 \pm 0.06$ and 

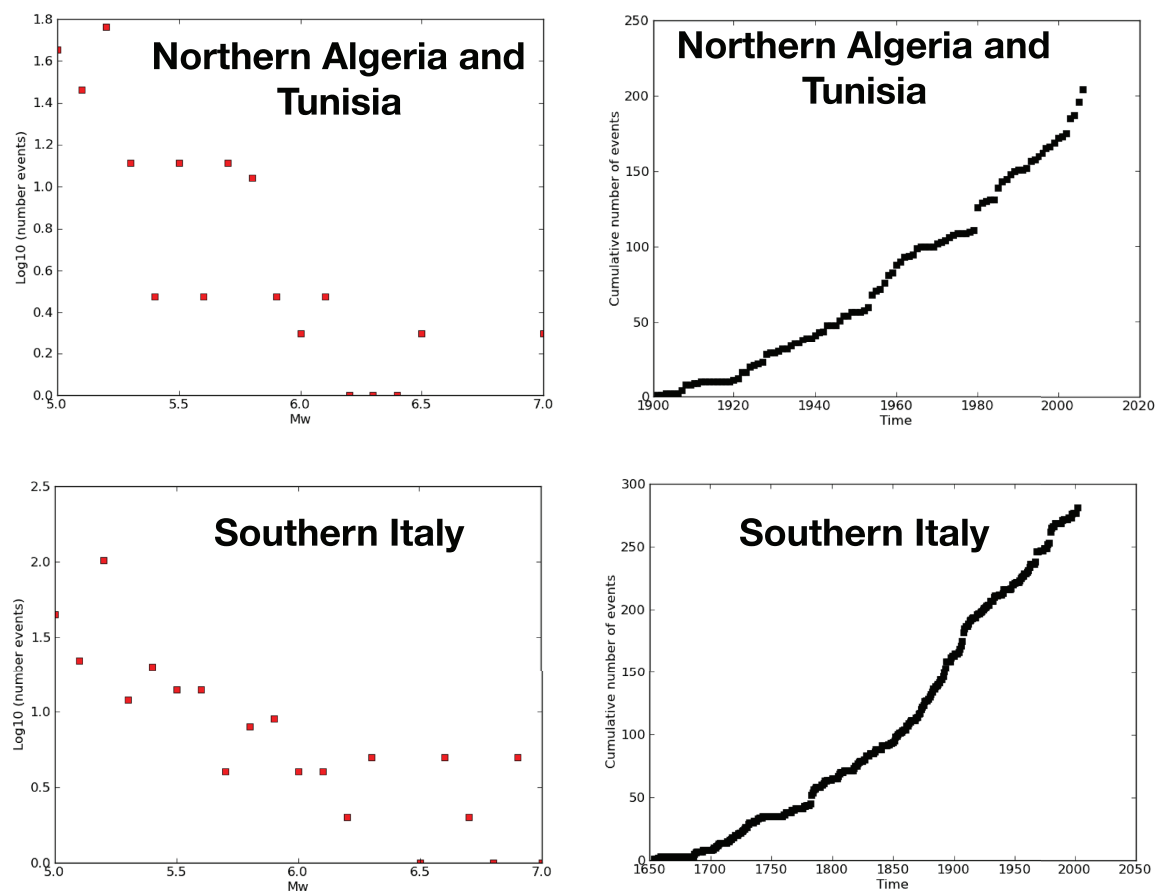

Figure 9. Cumulative number of earthquake (right panels) and the Gutenberg-Richer law (left panels) for the two area under examination: Northern Algeria and Tunisia (West of the Tyrrhenian Sea) on top, and Southern Italy (Southern Tyrrhenian Sea)on the bottom.

$1.15 \pm 0.6$ for the Italian and African areas, respectively. To connect GR distribution to single scenarios for propagation, the complete range of magnitudes is divided in $n_{k}$ intervals $\left[M_{k}^{\min }, M_{k}^{\max }\right]$. A probability of occurrence is assigned at each interval following the truncated Gutenberg-Richter distribution. Following Selva et al. (2016), the assigned probability is the one corresponding to the minimum magnitude $M_{k}^{\text {min }}$ since it represents the mode (most frequent) magnitude of the interval. In general, this choice does not affect the results if the magnitude intervals are small enough.

Node 3: depth of the fault. The geometrical centers of the faults are distributed in a range of three possible depths $(5,10$, and $15 \mathrm{~km})$. A portion of the defined depths is physically not possible for certain magnitudes and are rejected. The other remaining events are assumed equally probable.

Node 4: strike, dip, and rake angles. In each cell, we have only one combination of the angles with probability set to 1 .

The source probabilities from the event tree are combined with the conditional stepwise hazard curves reporting the probabilities that the $Z$ parameter overcomes the $z$ threshold levels at the coastal sites.

4.1.2. $P T H A_{S M F}$

The event tree approach for the source probabilities for the $S M F$ case is schematized as follows:

Node 1: event occurrence in the grid cell. The probability is calculated by the formula $1-e^{-\lambda_{S M F} \Delta t}$, where $\lambda_{S M F}$ is the annual rate of occurrence of the $S M F$ s and $\Delta t$ is the exposure window. The $\lambda_{S M F}$ is 0.0004 /years for all the source area and is computed using geological investigations and instrumental data recorded in the Tyrrhenian Sea by Grezio et al. (2012).

Node 2: spatial probability. Spatial weights are introduced to represent the failure probability of the submarine masses. Some predominant geomorfological features can be identified as spatial general controlling factors and assigned to the cells as weights when the detailed geotechnical information (Locat \& Lee, 2002) is not available for an adequate slope stability analysis (details in Grezio et al., 2015, 2012, and Grilli et al., 2009, 2015):

(a) slope angles and depths of the center of mass affect the propensity of failure (Masson et al., 2006);

(b) scars of past mass failures left unstable margins (Martel, 2004);

(c) earthquake occurrences increase slide instability (Biscontin et al., 2004). 
The earthquake load increases the instability and the consequent $S M F$ s probability of occurrence. As a consequence, a factor $F_{S}$ related to the horizontal peak ground acceleration $(P G A)$ is computed following Booth et al. (1985) to indicate instability $\left(F_{S}<1\right)$, limit equilibrium $\left(F_{S}=1\right)$, and stability $\left(F_{S}>1\right)$ in the cells. The $P G A$ values are based on the probability of exceedance of $10 \% \mathrm{~g}$ in 50 years, as commonly done in seismic codes (CEN, 2004). The evaluation of the PGA is based on the SSS model discussed in section 4.1.1. To evaluate the ground motion, we use the simulation of 10,000 catalogs that follows the Poisson distribution (as in Faenza et al., 2007, 2015, 2017). Subsequently, the ground motion of each event is calculated using the ground motion prediction equation by Akkar and Bommer (2010) in each node of the grid in Figure 2. Then, the probability of exceedance of $10 \%$ in 50 years is derived directly from the percentile of the empirical ground data for each cell (see Faenza et al., 2007, 2015, 2017). In the cells where the past SMFs occurred (Figure 4 and Table 1), the weights are incremented. The spatial weights and the stability factors of section 3.1.2 are converted in spatial probability by normalization to 1 and are associated to the cell centers in the Tyrrhenian Sea (Grezio et al., 2012; Selva et al., 2012).

Node 3: slide volume. A frequency-size power law is calculated in order to weight the SMF classes. The corresponding $b$ value is calculated considering the available data in the Tyrrhenian Sea of Table 1 (Grezio et al., 2012). The size classes may correspond to slides or slumps and are uniformly associated to each grid cell.

Also in this case, the source probabilities are combined with the conditional probabilities for the evaluation of the $Z$ parameter overcoming the $z$ threshold levels at the coastal sites.

4.1.3. $P T H A_{P D C}$

The event tree approach for the source probabilities of the PDCs is the following:

Node 1: probability of at least one eruption from Somma-Vesuvio in the next 50 years. Such probability is calculated by the Poisson occurrence $1-e^{-\lambda_{P D C} \Delta t}$, where $\lambda_{P D C}$ is the annual rate of occurrence of eruptions at Somma-Vesuvio, and $\Delta t$ is the exposure window equal to 50 years. The $\lambda_{P D C}$ for Somma-Vesuvio is $8 \times 10^{-3}$ /year (Marzocchi et al., 2008).

Node 2: Probability of the eruptive vent. All eruptions are assumed being located on the summit of Somma-Vesuvio, with probability given an eruption at Somma-Vesuvio, equal to 1 following Tierz et al. (2018).

Node 3: probability of an eruption of small, or medium, or large size, given an eruption from the summit of Somma-Vesuvio. The categorization into small, medium, and large size is based on the total erupted mass, as in Sandri et al. (2016). The probability density function for the total erupted mass is based on a frequency-size power law, continuous on the whole spectrum of possible erupted mass values, as in Sandri et al. (2016). We consider all the simulations within a given size class as equiprobable. The probability distribution among the three size classes is instead set according to a power law based on the frequency of such classes in the geological record of Somma-Vesuvius (from Sandri et al., 2016).

Node 4: probability of $P D C$ generation, given an eruption of small, medium, or large size from Somma-Vesuvio. Here we rely on the statistics provided by Newhall and Hoblitt (2002), and adapted to Somma-Vesuvius by Sandri et al. (2018) and Tierz et al. (2018), for PDCs produced during the small, medium, and large eruption classes. In Newhall and Hoblitt (2002) no distinction on the density of the PDCs is made: But we assume that, given the generation of PDCs at Somma-Vesuvio, there will be generation of dense PDCs (Tierz et al., 2018). For the frequency of arrival at the coast by dense PDCs of different sizes, from Somma-Vesuvio summit, we use the TITAN2D simulations of Tierz et al. (2018) as explained in section 3.1.3.

Similarly to the $S M F$ and $S S S$ cases, the source probabilities are combined with the stepwise conditional probabilities.

As example, in Figure 12a, the prior SSS tsunami hazard curve is compared to the prior SMFs and the prior PDCs at the coastal points in the Gulf of Naples.

\subsection{Likelihood Module: Historical Tsunami Events}

The historical events for the likelihood are extracted by the Italian tsunami catalog (Maramai et al., 2014; Tinti et al., 2004) and listed in Table 3. In the catalog the events are ascribed to earthquake, volcanic, and slide 
Table 3

Historical Tsunami Events in the Gulf of Naples Reported by the Italian Tsunami Catalog

\begin{tabular}{lcclcc}
\hline Date (yy-mm-dd) & Latitude & Longitude & \multicolumn{1}{c}{ Cause and Description } & $T I$ & $R$ \\
\hline 79-08-24 & 40.49 & 14.26 & Volcano associated, sea retreat in Gulf of Naples & 2 & 2 \\
$1112-06-20$ & n.d. & n.d. & Unknown cause, sea withdrawal of about 200 steps & 2 & 2 \\
$1631-12-17$ & 40.49 & 14.26 & Volcano associated, sea withdrawal in Gulf of Naples & 2 & 4 \\
$1698-05-14$ & 40.49 & 14.26 & Volcano associated, sea oscillations in Gulf of Naples & 2 & 2 \\
$1714-06-30$ & 40.49 & 14.26 & Volcano associated, sea withdrawal in Gulf of Naples & 2 & 0 \\
$1760-05-16$ & 40.51 & 14.16 & Submarine earthquake, sea withdrawal in Portici & 2 & 2 \\
$1805-07-26$ & 41.3 & 14.28 & Earthquake associated, sea rise in Gulf of Naples & 2 & 4 \\
$1813-05-17$ & 40.49 & 14.26 & Volcano associated, sea withdrawal in Gulf of Naples & 2 & 1 \\
$1847-08-26$ & $n . d$. & $n . d$. & Unknown cause, sea level lowering in Naples & 2 & 0 \\
$1906-04-04$ & 40.49 & 14.26 & Volcano associated, sea oscillations in Gulf of Naples & 2 & 4 \\
\hline
\end{tabular}

Note. $T I=$ tsunami intensity; $R=$ reliability; $n . d=$ not determined (Maramai et al., 2014; Tinti et al., 2004).
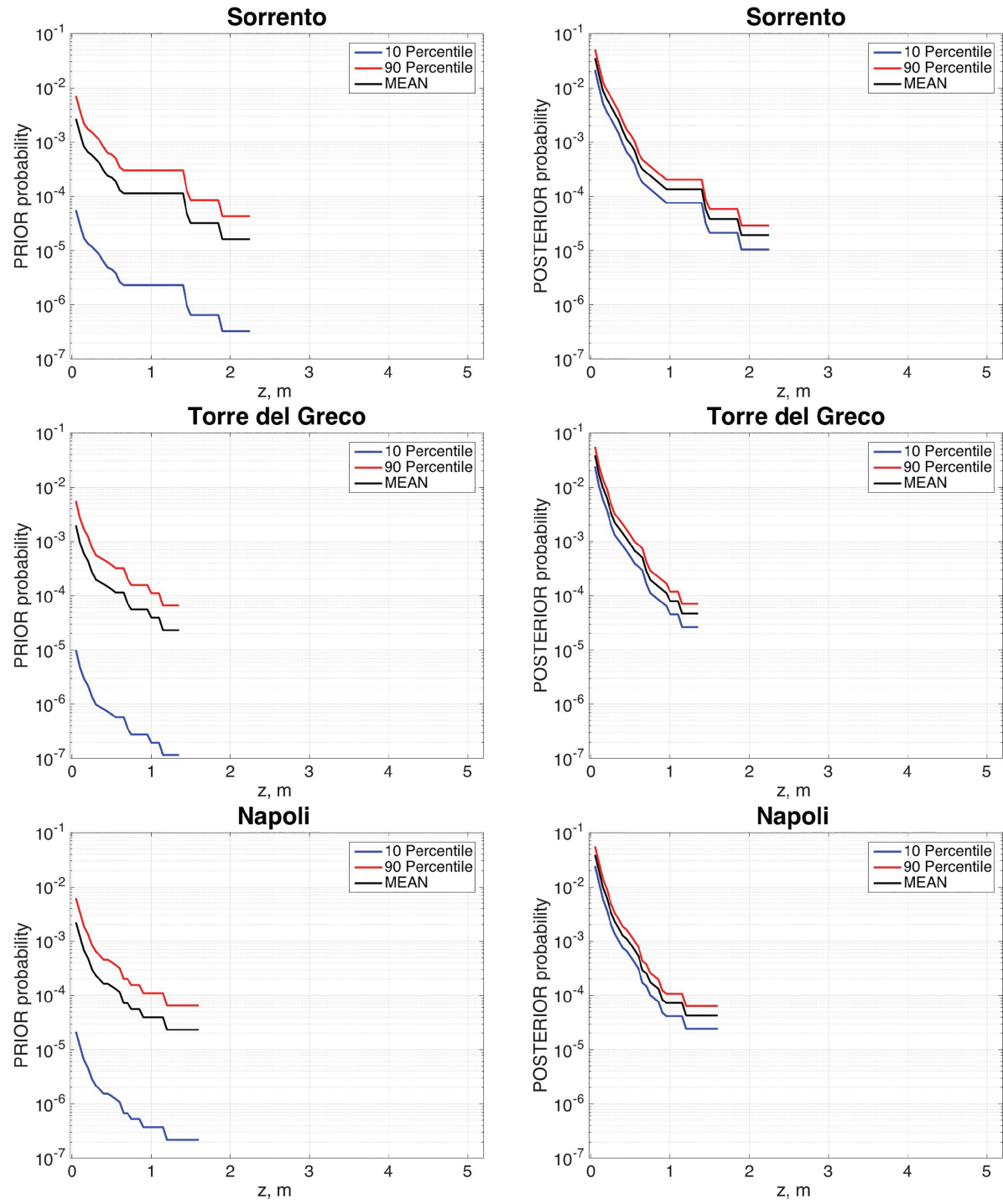

Figure 10. Tsunami hazard curves for Sorrento, Torre del Greco, and Napoli (site location indicated by numbers 1, 2, and 3 in Figure 2) showing the 10th percentile, the 90th percentile, and the mean of the prior and posterior probabilities. 

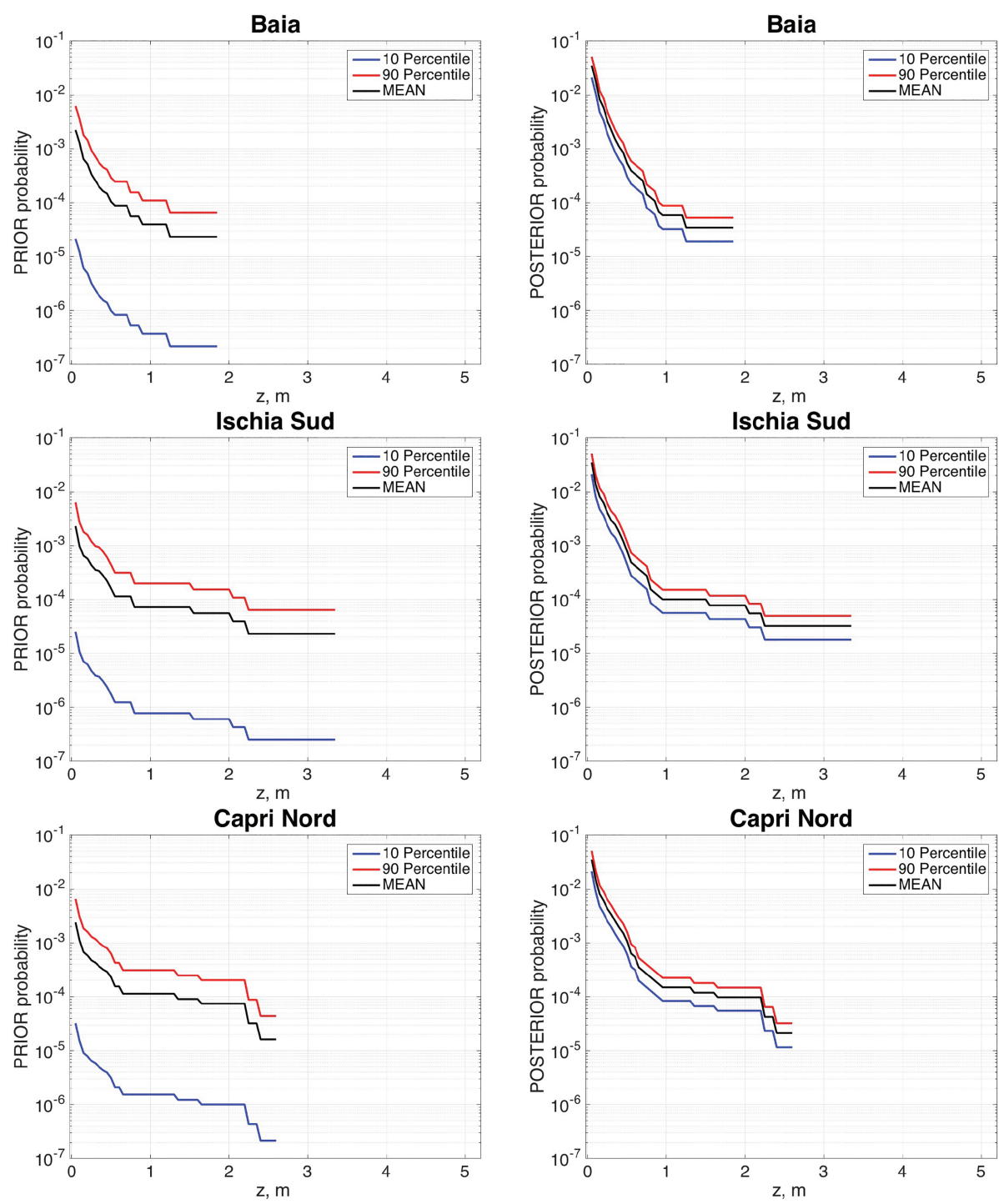

Figure 11. Tsunami hazard curves for Baia, Ischia Sud, and Capri Nord (site location indicated by numbers 4, 5, and 6 in Figure 2) showing the 10th percentile, the 90th percentile, and the mean of the prior and posterior probabilities.

sources, when this is documented. Nevertheless, in some cases the source events are reported as unknown. In order to maximize the number of information from the historical records and to include the unknown sources, we assume reasonably that the unknown sources could belong to one of the source types of the present study. The information selected in the tsunami catalog is the locations of the source, the causes, and the descriptions of the tsunami effects at the coast.

The tsunamis observed in the last 2,000 years in the Gulf of Naples were caused mainly by earthquakes and volcanic activity. The Ischia debris avalanche event was antecedent to the time interval covered by the Italian Tsunami Catalog, and, in any case, there is no evidence of Ischia avalanches that generated tsunamis in the area (Selva et al., 2019). Also, the tsunami intensity and the reliability are indicated in the catalog. The tsunami intensity ranges between 1 and 6, meaning, respectively, very weak tsunami and disastrous tsunami. The reliability is between 0 and 4 meaning, respectively, very improbable tsunami and a definite tsunami, according to the Ambraseys-Sieberg Scale.

Generally, it is recognized that an event of intensity $\geq 3$ produces runup of approximately $1 \mathrm{~m}$ (Tinti et al., 2005) while in the case of tsunami intensity equal 2, the estimation is not clear. In the present study, given that there are no data with intensity $\geq 3$, we prefer to recognize those historical data as valuable information for the likelihood calculation even if there is no explicit indication of the wave heights, wave amplitudes, 


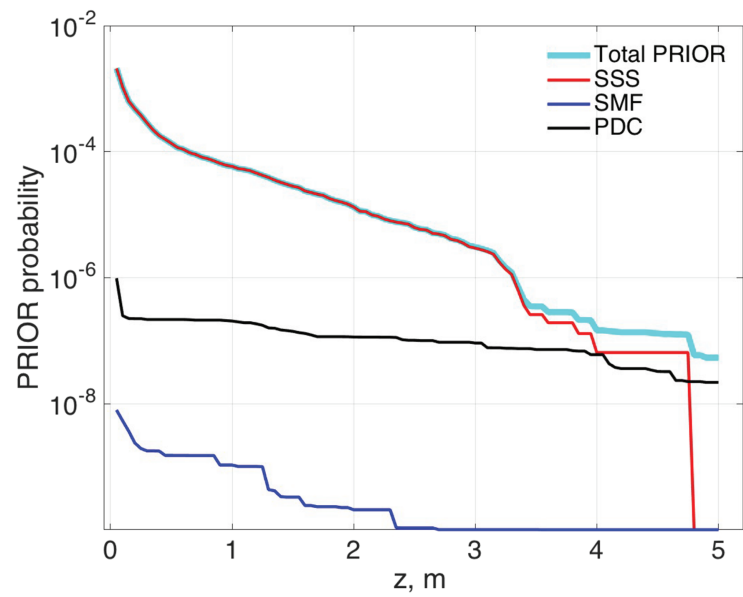

a)

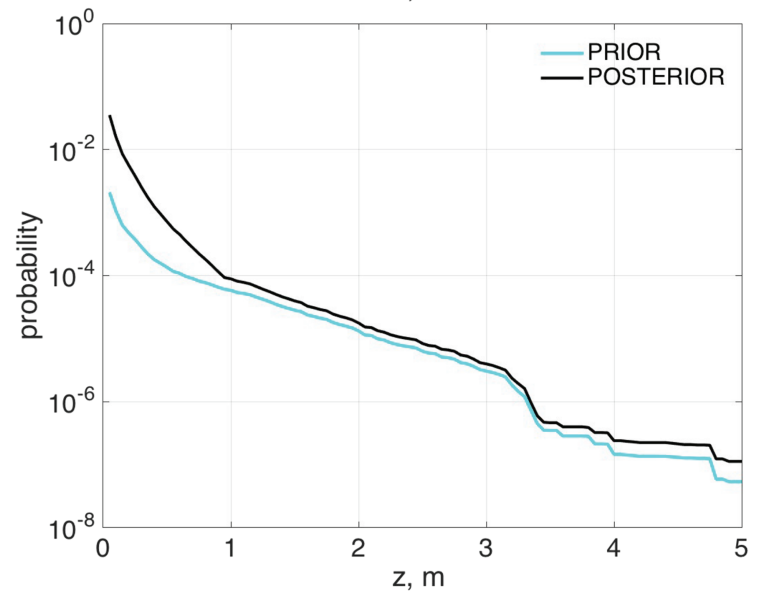

b)

Figure 12. (a) Tsunami hazard curves comparing the total, $S S S, S M F$, and $P D C$ prior probabilities and (b) prior and posterior hazard curves. The values are averaged over the coastal points of the Gulf of Naples for each $z$ level.

Table 4

Prior and posterior Mean Probabilities and the Relative 10th and 90th Percentiles Averaged Over the Total Coastal Points of the Impact Area Overcoming Different Threshold Levels in the Exposure Time of 50 Years

\begin{tabular}{lcccccc}
\hline \multicolumn{3}{c}{ Prior } \\
\hline $\mathrm{m}$ & 10 th percentile & Mean & 90 th percentile & 10th percentile & Mean & 90 th percentile \\
0.1 & $1.3 \times 10^{-5}$ & $1.0 \times 10^{-3}$ & $3.0 \times 10^{-3}$ & $9.4 \times 10^{-3}$ & $1.6 \times 10^{-2}$ & $2.3 \times 10^{-2}$ \\
0.5 & $1.7 \times 10^{-6}$ & $1.4 \times 10^{-4}$ & $3.7 \times 10^{-4}$ & $4.1 \times 10^{-4}$ & $7.2 \times 10^{-4}$ & $1.1 \times 10^{-3}$ \\
1.0 & $6.9 \times 10^{-7}$ & $5.8 \times 10^{-5}$ & $1.6 \times 10^{-4}$ & $5.0 \times 10^{-5}$ & $8.9 \times 10^{-5}$ & $1.3 \times 10^{-4}$ \\
1.5 & $4.0 \times 10^{-7}$ & $2.8 \times 10^{-5}$ & $7.7 \times 10^{-5}$ & $2.2 \times 10^{-5}$ & $4.0 \times 10^{-5}$ & $6.0 \times 10^{-5}$ \\
2.0 & $2.0 \times 10^{-7}$ & $1.3 \times 10^{-5}$ & $3.6 \times 10^{-5}$ & $9.8 \times 10^{-6}$ & $1.8 \times 10^{-5}$ & $2.7 \times 10^{-5}$ \\
2.5 & $1.0 \times 10^{-7}$ & $6.3 \times 10^{-6}$ & $1.7 \times 10^{-5}$ & $4.6 \times 10^{-6}$ & $8.4 \times 10^{-6}$ & $1.3 \times 10^{-5}$ \\
3.0 & $5.7 \times 10^{-8}$ & $3.0 \times 10^{-6}$ & $8.3 \times 10^{-6}$ & $2.2 \times 10^{-6}$ & $4.0 \times 10^{-6}$ & $6.0 \times 10^{-6}$ \\
3.5 & $7.9 \times 10^{-9}$ & $3.5 \times 10^{-7}$ & $9.4 \times 10^{-7}$ & $2.5 \times 10^{-7}$ & $4.6 \times 10^{-7}$ & $7.2 \times 10^{-7}$ \\
4.0 & $1.3 \times 10^{-9}$ & $1.5 \times 10^{-7}$ & $4.0 \times 10^{-7}$ & $1.3 \times 10^{-7}$ & $2.4 \times 10^{-7}$ & $3.8 \times 10^{-7}$ \\
4.5 & $1.2 \times 10^{-9}$ & $1.3 \times 10^{-7}$ & $3.7 \times 10^{-7}$ & $1.1 \times 10^{-7}$ & $2.1 \times 10^{-7}$ & $3.3 \times 10^{-7}$ \\
5.0 & $1.4 \times 10^{-10}$ & $5.4 \times 10^{-8}$ & $1.5 \times 10^{-7}$ & $5.8 \times 10^{-8}$ & $1.1 \times 10^{-7}$ & $1.8 \times 10^{-7}$ \\
\hline
\end{tabular}



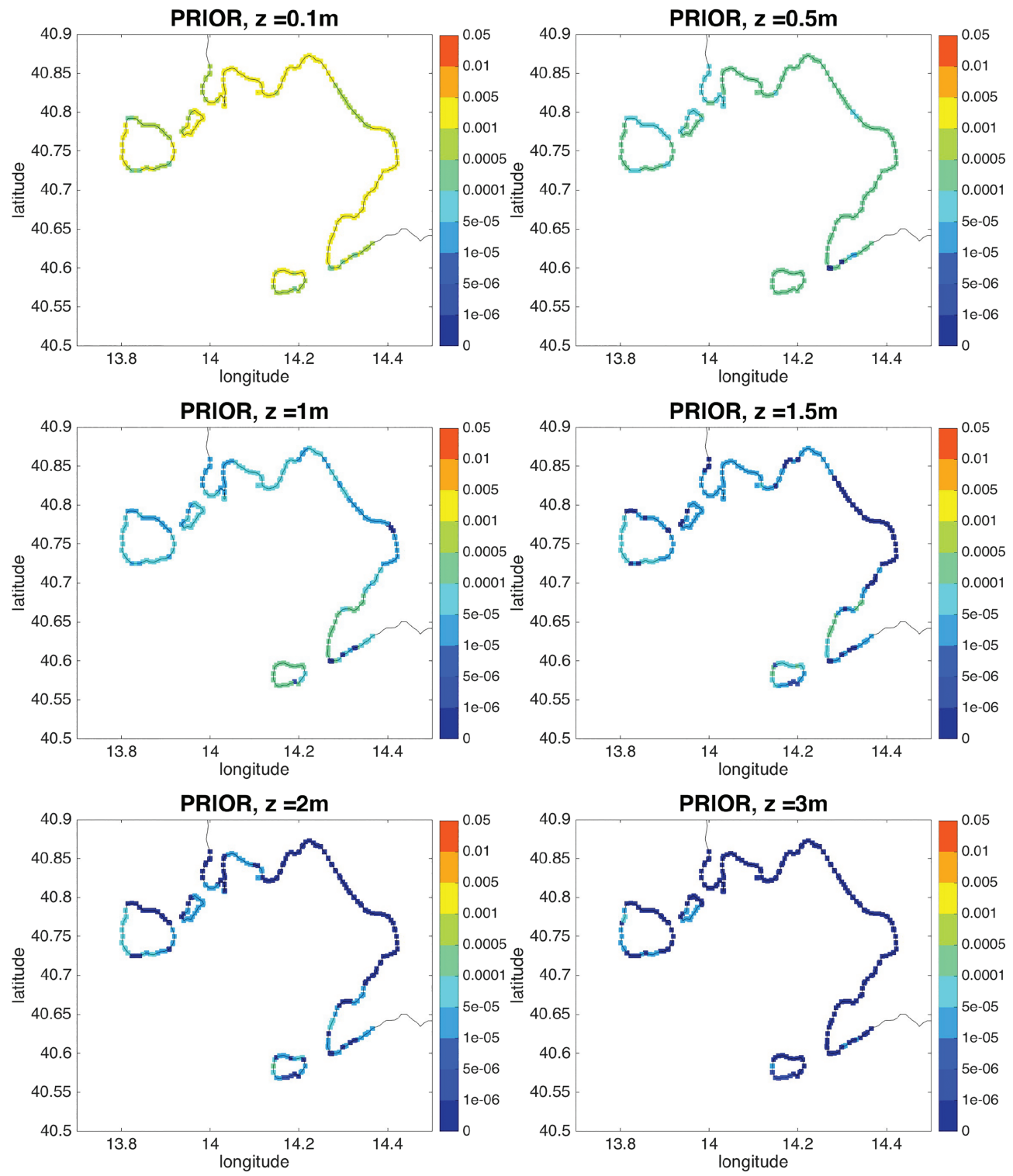

Figure 13. Tsunami probability maps. The prior mean probabilities for the threshold levels of $0.1,0.5,1.0,1.5,2.0$, and $3.0 \mathrm{~m}$ are shown for the coastal points in the Gulf of Naples.

or runups. We do not ignore those data, and we assume that they produce a tsunami just lower than $1 \mathrm{~m}$. They influence the hazard curves of the tsunami parameters intensity $<1 \mathrm{~m}$ and the probabilities that the $Z$ parameter overcomes the $z$ threshold levels below $1 \mathrm{~m}$.

The likelihood in equation (10) is computed on the basis of the historical data $y$ occurred in the Gulf of Naples assuming that the observations form a complete catalog in its period of coverage. In the time window of 50 years, the $y$ years are counted as success $f u l$ events when the tsunamis are observed. In the same time window, the years $(n-y)$ without tsunamis are the unsuccess $f u l$ events in the Binomial model of equation (9). Finally, the successful events affect the estimation of the probability of the $Z$ parameter overcoming the $z$ thresholds in the posterior analysis.

\subsection{Posterior Module: Long-Term PTHA}

The posterior module computes the posterior probability density distribution $[P \mid Y]_{\text {post }}$ of equation (11). This Beta distribution is the prior Beta distribution modified by the Binomial model of the likelihood, both described in sections 4.1 and 4.2. The prior probability is the probability of the tsunami scenarios based 

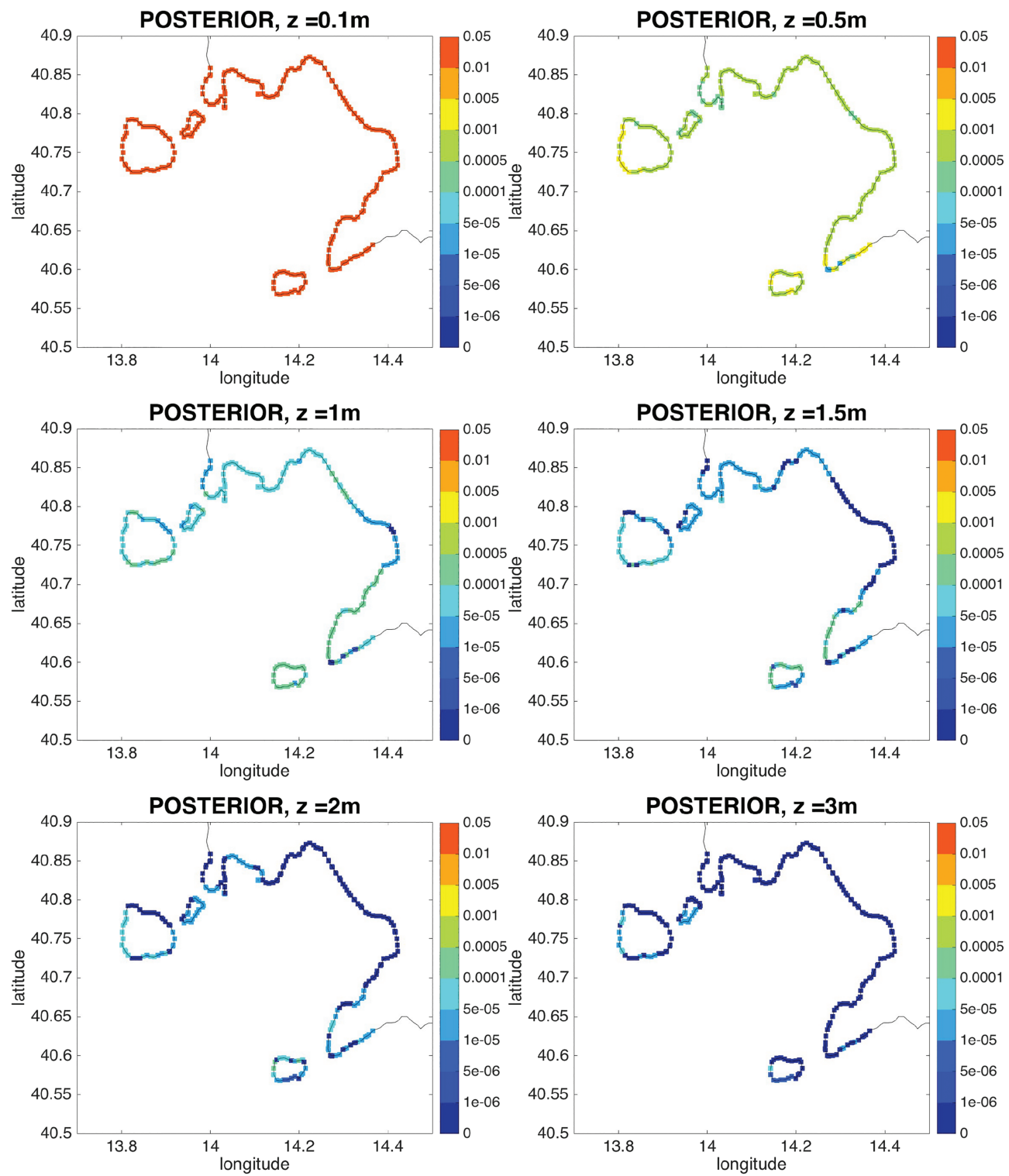

Figure 14. Tsunami probability maps. The posterior mean probabilities for the threshold levels of $0.1 \mathrm{~m}, 0.5 \mathrm{~m}, 1.0 \mathrm{~m}$, $1.5 \mathrm{~m}, 2.0 \mathrm{~m}$ and $3.0 \mathrm{~m}$ are shown for the coastal points in the Gulf of Naples.

on the statistical and numerical modeling, geological knowledge, and tectonics of the region. The posterior probability includes the historical records of the tsunami catalog and the historical data $y$ in the analysis.

The posterior probability density distributions provide the tsunami hazard curves and indicate the probabilities (and the relative epistemic uncertainties) that tsunamis occur in the time window $\Delta t$ of 50 years overcoming the $z$ threshold levels at the coastal sites in the Gulf of Naples. The values of the prior and posterior probability are different at each costal point. Generally, the posterior probabilities increase respect to the prior probabilities for intensity smaller than $1 \mathrm{~m}$. In some cases the posterior values are 1 order of magnitude higher or more than the prior values (Figures 10 and 11). The mean of the posterior probability density distributions represents the best estimate of the process under investigation and the 10th and 90th percentiles are an estimate of the epistemic uncertainty (Gelman et al., 2013).

Figure 12a shows the SSS, SMF, and PDC probabilities belonging to the corresponding types of sources comparing their single contributions to the total prior. The values of the hazard curves are averaged over the points of the Gulf of Naples at each $z$ level. Figure $12 \mathrm{~b}$ presents the tsunami prior and posterior hazard curves with the probabilities averaged over the points of the Gulf of Naples at each $z$ level. In this case the 
most significant differences are related to the probabilities that tsunami wave heights at the coastal points overcome the threshold levels lower than $1 \mathrm{~m}$ because the historical tsunami events are taken into account.

Table 4 summarizes the analysis presenting the mean values of the prior and posterior probability density distributions and the 10th and 90th percentiles averaged over the total coastal sites of the impact area for different $z$ levels from 0.1 to $5.0 \mathrm{~m}$.

The tsunami probability maps are obtained by vertical cuts of the tsunami hazard curves and are a geographical representation of the tsunami intensity probability distribution. In Figures 13 and 14 the maps are presented, respectively, for the mean prior and posterior tsunami probabilities and are selected at $0.1,0.5$, $1.0,1.5,2$, and $3 \mathrm{~m} z$ levels. Spatial differences are due to both the morphology of the coast and the local historical events listed in Table 3 and included in the Bayesian analysis.

\section{Discussion and Conclusions}

The city of Naples and the surrounding areas experienced relevant threats due to natural hazards in the past. In the present time, the high densely populated districts in the Campania region constitute the crucial factor in the risk assessments related to destructive natural events (earthquakes, volcanic eruptions, landslides, and tsunamis). For the first time a probabilistic analysis of the tsunami hazard in the region is presented taking into account multiple tsunamigenic sources. The hazards of different tsunamigenic sources are evaluated in the same probabilistic framework for a comprehensive Bayesian PTHA.

The major scopes of long-term multisource Bayesian PTHA are as follows:

1) reducing the possible biases and to avoid PTHA underestimations by focusing only on a single source (generally the seismic one) if other tsunamigenic sources are not negligible (Grezio et al., 2015);

2) obtaining a more complete evaluation of the tsunami hazard in a multihazard context (Selva, 2013);

3) including the historical tsunami data in the PTHA applying the Bayes' theorem (Grezio et al., 2017). The multisource $P T H A$ considers different types of sources, which may potentially generate tsunami waves. The methodology is general and can be extended to other areas exposed to tsunamis due to multiple sources.

The evaluation of unbiased hazard quantifications is particularly critical in densely inhabitated areas, where even minor contributions may be provide important contribution for risk reduction. This is the case of the Gulf of Naples, where we apply the proposed method. In this application, the simplifications are introduced in order to present the methodology and to provide a very first-order prioritization of the different sources.

The present methodology follows a modular procedure, and it is possible to group the modules in two categories: (a) the series of steps to produce the tsunami waves reaching the coastal sites and (b) the series of steps to formalize the probabilistic evaluations.

The first set of modules (Source, Propagation, and Impact) produces three data sets of possible tsunami wave scenarios belonging to the different types of sources. In this hazard analysis three types of tsunamigenic sources are selected: submarine seismic sources in the Tyrrhenian Sea and North-African Mediterranean Sea, submarine mass failures in the Tyrrhenian Sea, and dense pyroclastic density currents from Somma-Vesuvius.

For volcanic sources, this study focuses only PDCs from Somma-Vesuvius. Among the many different potential volcanic sources, only the Somma-Vesuvius eruptions have left geological evidence of tsunamigenesis reaching the Gulf of Naples due to dense PDCs entering the sea (Tinti et al., 2004). Other potential volcanic sources include the underwater explosions at the Campi Flegrei (Paris et al., 2019); lahar flows entering the sea (Paris et al., 2014; Tierz et al., 2017); potential submarine volcanic activity from other volcanoes such as Marsili, Palinuro, and Vavilov (Caratori Tontini et al., 2010); and the insular volcanoes (as Ischia, Stromboli, Salina, and Vulcano) (Paparo \& Tinti, 2017; Selva et al., 2019).

Apart from a volcanic source, there are potential submarine faults and submarine landslides, which are difficult to localize because of the paucity of information and data collected at the Tyrrhenian Sea. Moreover, in a probabilistic approach the spatial identification of the potential sources must be as wide as possible without a priori restriction on a particular fault or slide volume. The adopted strategy for SSSs and SMFs is the use of a gridded domain where the source area is divided in cells in which the potentially tsunamigenic source 
events are identified and defined by a set of parameters. These parameters characterize each source geometry that is used to model the ocean floor deformation corresponding to the sea surface initial tsunami wave. The range of source parameters is capable to fully describe the potential tsunamigenic sources associated to the cell centers. In this application several important simplifications are introduced to reduce the computational effort. In the Source Module, all identified scenarios are simulated with the use of three numerical models (COMCOT, SPHysics, and Titan2D), and the relative outputs are organized in cascade to generate and propagate the potential tsunami waves. In the Wave Module each initial tsunami wave is propagated in the Gulf of Naples. Then, the tsunami wave amplitudes at the $50 \mathrm{~m}$ depth are used by an amplification law to evaluated the tsunami amplitudes at the coastal points in the Impact Module.

The second set of modules (Prior, Likelihood, and Posterior) evaluates the probability that the tsunami wave of a wide range of tsunami scenarios overcomes the selected threshold levels at the coast with the scope of producing hazard curves and hazard maps for the PTHA in the Gulf of Naples. In the prior module the probability density distributions evaluate the noninteractive and conditional probabilities of the tsunami scenarios by incorporating the present state of knowledge, the theoretical understanding of the tsunami process in the region, and the tsunami modeling. The noninteractive probabilities for each type of source are evaluated by event trees, in a procedure similar to Selva et al. (2016), and extended to all the considered sources. As a consequence, the hazard analysis is homogeneous in the probabilistic framework. Spatial, temporal, and frequency-size probabilities of occurrence of the sources events belonging to the different source types (SSSs, SMFs, and PDCs) are associated to the simulated scenarios of the tsunami waves overcoming the $z$ levels through conditional hazard curves, based on simulation results. Here, in this application, we neglect all the potential associated uncertainty, adopting stepwise hazard curves.

In the likelihood module the probabilistic analysis includes the historical information and the past tsunami data from the Italian Tsunami Catalogue and the background papers. Being all sources formally included in the prior, it is not necessary a selection of past events based on the causative type of source. However, it is important to work in the conversion between the hazard intensity available from historical data toward the hazard intensity adopted in PTHA. In our application, we strongly simplified this passage, and more attention should be given in the future to this issue to enable a more robust consideration of past data in hazard quantifications. The posterior probability density distributions are computed merging the prior probabilistic analysis and the likelihood of the historical data in the Posterior Module. This allows producing tsunami hazard curves and maps that account for both source modeling and past data.

The modular procedure certainly increases complexity in the probabilistic analysis. For this reason, we intentionally kept simple the developed application.

The present analysis is mainly methodological, and simplifications can be reduced in subsequent probabilistic hazards analyses. Major limitations are due to the simplifications for source generation processes and the tsunami waves near the coast. For example, future improvements should consider the following:

a. the use of empirical relationships like the Green's law should be abandoned,

b. the bathymetry resolution near the coast has to be represented by an adequate grid of higher resolution for all types of sources,

c. the impact velocity of the pyroclastic density currents need to be to included in the different $P D C$ s scenarios. Certainly, these limitations may be addressed implementing more advanced methods and updated modeling approaches in future studies aimed to a comprehensive PTHA of the Gulf of Naples, including also submarine explosive eruptions or other tsunamigenic sources, which have been neglected here,

d. more sophisticated models of the submarine mass failures need to be implemented, and

e. the overall discretization of the parameter space of sources (e.g. location and magnitude) must be improved by thickening the gridded domain.

However, the structure permits to include further modifications and subsequent improvements to the $P T H A$ in case of different types of sources. For example, further improvements may include the following:

a. updating of the methodologies and a wider range of moment tensors and the inclusion of the recent submarine earthquakes in the region in the case of the seismic sources;

b. including the subaerial slides at the Isle of Ischia in the case of the mass failures;

c. considering the underwater explosions in the Campi Flegrei caldera in the case of the volcanic sources (Paris et al., 2019); 
d. implementing the wave dispersion modeling (Glimsdal et al., 2013) in the Propagation Module; e. using more accurate amplification factors (Glimsdal et al., 2019) in the Impact Module.

The first-order tsunami hazard results in the Gulf of Naples indicate that in average the probabilities of the tsunami waves overcoming $0.1,0.5,1.0$, and $2.0 \mathrm{~m}$ at the coast are, respectively, $1.6 \times 10^{-2}, 7.2 \times 10^{-4}$, $8.9 \times 10^{-5}$, and $1.8 \times 10^{-5}$ in the exposure time of 50 years.

The majority of the costal sites overcome the thresholds below $0.5 \mathrm{~m}$ with similar probabilities, a part the isles where the spatial differences depend mainly on the local factors (as the bathymetry and morphology of the coast). The highest probabilities to overcome levels of about 1-1.5 $\mathrm{m}$ in 50 years occur at the city of Naples, the Campi Flegrei area, and the Ischia Island.

In conclusion, we propose the multisource Bayesian PTHA as a general modular procedure for the estimates of the long-term tsunami hazard in a highly populated coastal regions where it is crucial to reduce the risk posed by different natural threats.

\section{Acknowledgments}

This study was supported by the Italian national project ByMuR (Bayesian Multi-Risk Assessment: A case study for natural risks in the city of Naples) financed by MIUR, the Italian Ministry for Research and Education. The RCMT Catalog is available at the INGV-RCMT website (http://rcmt2.bo. ingv.it). The EMMA Database is available at the EMSC website (https:// www.emsc-csem.org/Earthquake/ emma.php). The $G E B C O$ bathymetry data are available at the GEBCO website( https://www.gebco.net/data\& urluscore;and\&urluscore;products/ gridded\&urluscore; bathymetry\& urluscore;data/). The high-resolution bathymetry data of the Gulf of Naples are available upon request contacting the corresponding author. It was provided by Giuseppe Villardo from the "Laboratory of Geomatics and Cartography" of the Istituto Nazionale di Geofisica e Vulcanologia - sezione di Napoli, Osservatorio Vesuviano. Some results shown here were obtained through computational resources provided by the Center for Computational Research, University at Buffalo, NY, USA, and received funding from the EU FP7 project NEMOH (Numerical, Experimental and stochastic Modeling of vOlcanic processes and Hazard, Grant Agreement 289976). We thank the editor Ryan Lowe and reviewer Raphaël Paris for their valuable comments that improved the quality of the paper.

\section{References}

Akkar, S., \& Bommer, J. J. (2010). Empirical equations for the prediction of PGA, PGV and spectral accelerations in Europe, the Mediterranean and the Middle East. Seismological Research Letters, 81, 195-206.

Barkan, R., ten Brink, U. S., \& Lin, J. (2009). Far field tsunami simulations of the 1755 Lisbon earthquake: Implications for tsunami hazard to the U.S. East Coast and the Caribbean. Marine Geology, 264, 109-122.

Biscontin, G., Pestana, J., \& Nadim, F. (2004). Seismic triggering of submarine slides in soft cohesive soil deposits. Marine Geology, 354, 203-341.

Booth, J., Sangrey, D., \& Fugate, J. (1985). A nomogram for interpreting slope stability of fine-grained deposits in modern and ancient marine environments. Journal of Sedimentary Petrology, 36, 29-36.

CEN (2004). Eurocode 8: Design of structures for earthquake resistance-Part 1: General rules, seismic actions and rules for buildings. Authority: The European Union Per Regulation 305/2011, Directive 98/34/EC, Directive 2004/18/EC.

Calvari, S., Spampinato, L., Lodato, L., Harris, A. L., Patrick, M., Dehn, J. B., \& Andronico, D. (2005). Chronology and complex volcanic processes during the 2002-2003 flank eruption at Stromboli volcano (Italy) reconstructed from direct observations and surveys with a handheld thermal camera. Journal of Geophysical Research, 110, B02201. https://doi.org/1029/2004JB003129

Caratori Tontini, F., Cocchi, L., Muccini, F., Carmisciano, C., Marani, M., Bonatti, E., et al. (2010). Potential field modeling of collapse prone submarine volcanoes in the southern Tyrrhenian Sea (Italy). Geophysical Res Letters, 37, L03305. https://doi.org/10.1029/2009GL041757

Davies, G., Griffin, J., Løvholt, F., Glimsdal, S., Harbitz, C., Thio, H. K., et al. (2017). A global probabilistic tsunami hazard assessment from earthquake sources. Geological Society, London, Special Publications, 456, 219-244. https://doi.org/10.1144/SP456.5

de Alteriis, G., Insinga, D., Morabito, S., Morra, V., Chiocci, F., Terrasi, F., et al. (2010). Age of submarine debris avalanches and tephrostratigraphy offshore Ischia Island, Tyrrhenian Sea, Italy. Marine Geology, 278, 1-18.

Della Seta, M., Marotta, E., Orsi, G., de Vita, S., Sansivero, F., \& Fredi, P. (2012). Slope instability induced by volcano-tectonics as an additional source of hazard in active volcanic areas: the case of Ischia Island (Italy). Bulletin of Volcanology, 106, 74-79.

Fabbri, A., Gallignani, P., \& Zitellini, N. (1981). Geologic evolution of the peri-Tyrrhenian sedimentary basins. In FC Wezel (Ed.), Sedimentary basins of the Mediterranean margins (pp. 101-126). Bologna, Italy: Technoprint.

Faenza, L., Heinz, S., Schermaus, F., \& Blauwal, C. (2007). Statistical analysis of time-dependent earthquake occurrence and its impact on hazard in the low seismicity region Lower Rhine Embayment. Geophysical Journal International, 171(2), 797-806. https://doi.org/10. 1111/j.1365-246X.2007.03564.x

Faenza, L., Pierdominici, S., Camassi, R., Michelini, A., Ercolani, E., \& Lauciani, V. (2013). The ShakeMap Atlas for the City of Naples Italy. Seismological Research Letters, 84(6), 963-972. https://doi.org/10.1785/0220130048

Faenza, L., Pierdominici, S., Hainzl, S., Cinti, F. R., Sandri, L., Selva, J., et al. (2017). A Bayesian seismic hazard analysis for the city of Naples. Journal of Geophysical Research: Solid Earth, 122, 1990-2012. https://doi.org/10.1002/2016JB013507

Frankel, A. (1995). Mapping seismic hazard in the central and eastern United States. Seismological Research Letters, 66, 8-21.

Gelman, A., Carlin, J. B., Stern, H. S., \& Rubin, D. B. (2013). Bayesian data analysis (pp. 667). New York: Chapman \& Hall/CRC Press.

Glimsdal, S., Løvhol, tF., Harbitz, C. B., Romano, F., Lorito, S., Orefice, S., et al. (2019). A new approximate method for quantifying tsunami maximum inundation height probability. Pure and Applied Geophysics, 176, 3227-3246. http://doi.org/10.1007/s00024-019-02091-w

Glimsdal, S., Pedersen, G. K., Harbitz, C. B., \& Løvholt, F. (2013). Dispersion of tsunamis: Does it really matter? Natural Hazards and Earth System Sciences, 13, 1507-1526. https://doi.org/10.5194/nhess-13-1507-2013

González-Vida, J. M., Macías, J., Castro, M. J., Sánchez-Linares, C., de la Asunción, M., Ortega-Acosta, S., \& Arcas, D. (2019). The Lituya Bay landslide-generated mega-tsunami. Numerical simulation and sensitivity analysis. Natural Hazards and Earth System Sciences, 19 , 369-388. https://doi.org/10.5194/nhess-19-369-2019

Grezio, A., Babeyko, A., Baptista, M. A., Behrens, J., Costa, A., Davies, G., et al. (2017). Probabilistic tsunami hazard analysis: Multiple sources and global applications. Reviews of Geophysics, 55, 1158-1198. https://doi.org/10.1002/2017RG000579

Grezio, A., Lorito, S., Parsons, T., \& Selva, J. (2017). Tsunamis: Bayesian probabilistic hazard analysis. In R. A. Meyers (Ed.), Encyclopedia of Complexity and Systems Science (pp. 1-25): Springer Publishing. https://doi.org/10.1007/978-3-642-27737-5\&urluscore;645-1

Grezio, A., Marzocchi, W., Sandri, L., \& Gasparini, P. (2010). A Bayesian procedure for probabilistic tsunami hazard assessment. Natural Hazards, 53, 159-174. http://doi.org/10.1007/s11069-009-9418-8.

Grezio, A., Sandri, L., Marzocchi, W., Argnani, A., \& Gasparini, P. (2012). Probabilistic tsunami hazard assessment for Messina Strait Area (Sicily-Italy). Natural Hazards, 64, 329-358.

Grezio, A., Tonini, R., Sandri, L., Pierdominici, S., \& Selva, J. (2015). A methodology for a comprehensive probabilistic tsunami hazard assessment: Multiple sources and short-term interactions. Journal of Marine Science and Engineering, 3, 23-51. https://doi.org/10.3390/ jmse3010023

Grilli, S. T., Taylor, S. O., Baxter, C. D. P., \& Maretzki, S. A. (2009). A probabilistic approach for determining submarine landslides tsunami hazard along the upper East Coast of the United States. Marine Geology, 264, 74-97. 
Grünthal G., Wahlstyrom, R., \& Journal of Seismology (2012). The European-Mediterranean Earthquake Catalogue (EME) for the last millennium, 16, 535-570. https://doi.org/10.1007/s10950-012-9302-y

Guidoboni, E., \& Boschi, E. (2006). Vesuvius before the 1631 eruption. Eos, 87(40), 3.

Gutenberg, B., \& Richter, C. (1944). Frequency of earthquakes in California. Bulletin of the Seismological Society of America, 34, $185-188$.

Ichihara, H., Hamano, Y., Baba, K., \& Kasay, T. (2013). Tsunami source of the 2011 Tohoku earthquake detected by an ocean-bottom magnetometer. Earth and Planetary Science Letters, 382, 117-124. https://doi.org/10.1016/j.epsl.2013.09.015

Ippen, A. T., \& Kulin, G. (1954). The shoaling and breaking of the solitary wave. Coastal Engegnering Proceedings, 1, 27-47.

Kamigaichi, O. (2009). Tsunami forecasting and warning. In R. Meyers (Ed.), Encyclopedia of Complexity and Systems Science (pp. 9592-9617). New York, NY, USA: Springer. https://doi.org/10.1007/978-0-387-30440-3

Kim, J., Løvholt, F., Issler, D., \& Forsberg, C. F. (2019). (Landslide material control on tsunami genesis-The Storegga Slide and tsunami (8100 y BP). Journal of Geophysical Research: Oceans, 124, 3607-3627. https://doi.org/10.1029/2018JC014893

Kostrov, B. V., \& Das, S. (1988). Principle of earthquake source mechanics, Applied Mathematics and Mechanics Series 286. Cambridge: Cambridge University Press.

Liu, P. L. F., Cho, Y. S., Briggs, M. J., Synolakis, C. E., \& Kanoglu, U. (1995). Run-up of solitary waves on a circular island. Journal of Fluid Mechanics, 302, 259-285. https://doi.org/10.1017/S0022112095004095

Liu, P. L. F., Cho, Y. S., Yoon, S. B., \& Seo, S. N. (1994). Numerical simulations of the 1960 Chilean tsunami propagation and inundation at Hilo, Hawaii. In M. I. El-Sabh (Ed.), Recent Development in Tsunami Research (pp. 99-115), Kluwer Academic Publishers. Dordrecht: Kluwer Academic Publishers.

Locati, M., Camassi, R., Rovida, A., Ercolani, E., Bernardini, F., Castelli, V., et al. (2016). DBMI15, the 2015 version of the Italian Macroseismic Database, Istituto Nazionale di Geofisica e Vulcanologia. http://doi.org/10.6092/INGV.IT?DBMI15

Lorito, S., Selva, J., Basili, R., Romano, F., Tiberti, M. M., \& Piatanesi, A. (2015). Probabilistic hazard for seismically induced tsunamis: Accuracy and feasibility of inundation maps. Geophysical Journal International, 200(1), 574-588. https://doi.org/10.1093/gji/ggu408

Lorito, S., Tiberti, M. M., Basili, R., Piatanesi, A., \& Valensise, G. (2008). Earthquake-generated tsunamis in the Mediterranean Sea: Scenarios of potential threats to Southern Italy. Journal of Geophysical Research, 113, B01301. https://doi.org/10.1029/2007JB004943

Løvholt, F., Bondevik, S., Laberg, J. S., Kim, J., \& Boylan, N. (2017). Some giant submarine landslides do not produce large tsunamis. Geophysical Research Letters, 44, 8463-8472. https://doi.org/10.1002/2017gl074062

Løvholt, F., Griffin, J., \& Salgado-Galvez, M. A. (2015). Tsunami hazard and risk assessment on the global scale. In R. A. Meyers (Ed.), Encyclopedia of Complexity and Systems Science (pp. 1-34). Heidelberg: Springer Berlin. https://doi.org/10.1007/978-3-642-27737-5\& urluscore;642-1

Løvholt, F., Harbitz, C. B., \& Haugen, K. B. (2005). A parametric study of tsunamis generated bysubmarine slides in the Ormen Lange/Storegga area off western Norway. Marine and Petroleum Geology, 22, 219-231. https://doi.org/10.1016/j.marpetgeo.2004.10.017

Løvholt, F., Pedersen, G., Harbitz, C., Glimsdal, S., \& Kim, J. (2015). On the characteristics of landslide tsunamis. Philosophical transactions. Series A Mathematical, physical, and engineering sciences, 373, 0376. https://doi.org/10.1098/rsta.2014.0376

Locat, J., \& Lee, H. J. (2002). Submarine landslides: Advances and challenges. Canadian Geotechnical Journal, 39, 193-212. https://doi. org/10.1139/T01-089

Løvholt, F., \& Urgeles, R. (2017). Towards a probabilistic tsunami hazard analysis for the Gulf of Cadiz, Proceedings of the European Geosciences Union General Assembly 2017 (pp. EGU2017-3657-1). Vienna. Apr. 8-13.

Macías, J., Mercado, A., Gonzávlez-Vida, J. M., Ortega, S., \& Castro, M. J. (2016). Comparison and numerical performance of Tsunami HySEA and MOST models for LANTEX 2013 scenario. Impact assessment on Puerto Rico coasts. Pure and Applied Geophysics, 173(12), 3973-3997. https://doi.org/10.1007/s00024-016-1387-8

Mansinha, L., \& Symlie, D. E. (1971). The displacement fields of inclined faults. Bulletin of the Seismological Society of America, 61(5), 1433-1440.

Maramai, A., Brizuela, B., \& Graziani, L. (2014). The Euro-Mediterranean Tsunami Catalogue. Annals of Geophysics, 57(4), S0435. https:// doi.org/10.4401/ag-6437

Martel, S. (2004). Mechanism of landslide initiation as a shear fracture phenomenon. Marine Geology, 203, 319-339.

Marzocchi, W., Garcia-Aristizabal, A., Gasparini, P., Mastellone, M. L., \& Di Ruocco, A. (2012). Basic principles of multi-risk assessment: A case study in Italy. Natural Hazards, 62, 551-573. https://doi.org/10.1007/s11069-012-0092-x

Marzocchi, W., Sandri, L., \& Selva, J. (2008). BET_EF: a probabilistic tool for long- and short-term eruption forecasting. Bull Volcanol, 70, 623-632. https://doi.org/10.1007/s00445-007-0157-y

Masson, D. G., Harbitz, C. B., Wynn, R. B., Pedersen, G., \& Løvholt, F. (2006). Submarine landslides: Processes, triggers and hazard prediction. Philosophical Transactions of the Royal Society A, 364, 2009-2039. https://doi.org/10.1098/rsta.2006.1810

Megawati, K., Shaw, F., Sieh, K., Huang, Z., Wu, T. R., Lin, Y., et al. (2009). Tsunami hazard from the subduction megathrust of the South China Sea: Part I. Source characterization and the resulting tsunami. Journal of Asian Earth Sciences, 36(1), 13-20. https://doi.org/10. 1016/j.jseaes.2008.11.012

Milia, A., Torrente, M., \& Giordano, F. (2006). Gravitational instability of submarine volcanoes offshore Campi Flegrei (Naples Bay, Italy) In B. De Vivo (Ed.), Volcanism in the Campania Plain: Vesuvius, Campi Flegrei and Ignimbrites (pp. 69-83). Naples, Italy: Elsevier, Developments in Volcanology, Universita' di Napoli Federico II.

Monaghan, J. J. (2005). Smoothed particle hydrodynamics. Reports on Progress in Physics, 68, 1703-1759. https://doi.org/10.1088/ 0034-4885/68/8/R01

Newhall, C. G., \& Hoblitt, R. P. (2002). Constructing event trees for volcanic crises. Bulletin of Volcanology, 64, 3-20. https://doi.org/10. $1007 / \mathrm{s} 004450100173$

Okada, Y. (1985). Surface deformation due to shear and tensile faults in a half-space. Bulletin of the seismological society of America, 75(4), $1135-1154$.

Paparo, M. A., \& Tinti, S. (2017). Analysis of seismic -driven instability of Mt. Nuovo in the Ischia Island, Italy. Bulletin of the seismological society of America, 107(2), 750-759. https://doi.org/10.1785/0120160139

Paris, R., Switzer, A. D., Belousova, M., Belousov, A., Ontowirjo, B., Whelley, P. L., \& Ulvrova, M. (2014). Volcanic tsunami: A review of source mechanisms, past events and hazards in Southeast Asia Indonesia, Philippines, Papua New Guinea. Natural Hazards, 70, 447-470.

Paris, R., Ulvrova, M., Selva, J., Brizuela, B., Costa, A., Grezio, A., et al. (2019). Probabilistic tsunami hazard analysis for tsunamis generated by subacqueos volcanic explosions in the Campi Flegrei caldera (Italy). Journal of Volcanology and Geothermal Research, 379, 106-116. https://doi.org/10.1016/j.jvolgeores.2019.05.010

Patra, A. K., Bauer, A. C., Nichita, C. C., Pitman, E. B., Sheridan, M. F., \& Bursik, M. (2005). Parallel adaptive numerical simulation of dry avalanches over natural terrain. Journal of Volcanology and Geothermal Research, 139(1-2), 1-21. https://doi.org/10.1016/j.jvolgeores 2004.06.014 
Perfetti, P., Tonini, R., Selva, J., Faenza, L., Grezio, A., \& Sandri, L. (2018). Management, visualization and comparison of multiple hazards and risk using free software: The ByMuR tool, Rapp. Tec. INGV 397, https://doi.org/10.5281/zenodo.1283839

Pondrelli, S., \& Salimbeni, S. (2015). Regional moment tensor review: An example from the European Mediterranean Region (pp. 1-15). Encyclopedia of Earthquake Engineering, Springer Berlin Heidelberg. http://link.springer.com/referenceworkentry/10.1007/ 978-3-642-36197-5\&urluscore;301-1

Pondrelli, S., Salimbeni, S., Ekström, G., Morelli, A., Gasperini, P., \& Vannucci, G. (2006). The Italian CMT dataset from 1977 to the present. Physics of the Earth and Planetary Interiors, 159(3-4), 286-303. https://doi.org/10.1016/j.pepi.2006.07.008

Power, W. L., Wang, X., Barberopoulou, A., \& Mueller, C. (2014). Validation of a deaggregation-based approach for tsunami evacuation mapping. GNS Science Report, 2014(36), 56.

Sandri, L., Costa, A., Selva, J., Tonini, R., Macedonio, G., Folch, A., \& Sulpizio, R. (2016). Beyond eruptive scenarios: Assessing tephra fallout hazard from Neapolitan volcanoes. Scientific Reports, 6(1), 24271. https://doi.org/10.1038/srep24271

Sandri, L., Tierz, P., Costa, A., \& Marzocchi, W. (2018). Probabilistic hazard from pyroclastic density currents in the Neapolitan area (Southern Italy). Journal of Geophysical Research: Solid Earth, 123, 3474-3500. https://doi.org/10.1002/2017JB014890

Selva, J. (2013). Long-term multi-risk assessment: Statistical treatment of interaction among risks. Natural Hazards, 67, 701-722. https:// doi.org/10.1007/s11069-013-0599-9

Selva, J., Acocella, V., Bisson, M., Costa, A., Caliro, S., De Martino, P., et al. (2019). Multiple natural hazards at volcanic islands: A review for the Ischia volcano (Italy). Journal of Applied Volcanology, 8(1), 5. https://doi.org/10.1186/s13617-019-0086-4

Selva, J., Orsi, G., Di Vito, M., Marzocchi, W., \& Sandri, L. (2012). Probability hazard map for future vent opening at the Campi Flegrei caldera, Italy. Bulletin of Volcanology, 74, 497-510. https://doi.org/10.1007/s00445-011-0528-2

Selva, J., \& Sandri, L. (2013). Probabilistic seismic hazard assessment: Combining Cornell-like approaches and data at sites through Bayesian inference. Bulletin of the Seismological Society of America, 103(3), 1709-1722. https://doi.org/10.1785/0120120091

Selva, J., Tonini, R., Molinari, I., Tiberti, M. M., Romano, F., Grezio, A., et al. (2016). Quantification of source uncertainties in Seismic Probabilistic Tsunami Hazard Analysis (SPTHA). Geophysical Journal International, 205, 1780-1803. https://doi.org/10.1093/gji/ggw107

Serpelloni, E., Vannucci, G., Pondrelli, S., Argnani, A., Casula, G., Anzidei, M., et al. (2007). Kinematics of the Western Africa-Eurasia plate boundary from focal mechanisms and GPS data. Geophysical Journal International, 169(3), 1180-1200.

Sørensen, M. B., Spada, M., Babeyko, A., Wiemer, S., \& Grünthal, G. (2012). Probabilistic tsunami hazard in the Mediterranean Sea. Journal of Geophysical Research, 117, B01305. https://doi.org/10.1029/2010JB008169

Sulpizio, R., Mele, D., Dellino, P., \& La Volpe, L. (2007). Deposits and physical properties of pyroclastic density currents during complex Subplinian eruptions: The AD 472 (Pollena) eruption of Somma-Vesuvius, Italy. Sedimentology, 54(3), 607-635. https://doi.org/10.1111/ j.1365-3091.2006.00852.x

Syamsidik, T., Rasyif, M., \& Kato, S. (2015). Development of accurate tsunami estimated times of arrival for tsunami-prone cities in Aceh, Indonesia. International Journal of Disaster Risk Reduction, 14(4), 403-410. https://doi.org/10.1016/j.ijdrr.2015.09.006

Tierz, P., Stefanescu, E. R., Sandri, L., Sulpizio, R., Valentine, G. A., Marzocchi, W., \& Patra, A. K. (2018). Towards quantitative volcanic risk of pyroclastic density currents: Probabilistic hazard curves and maps around Somma-Vesuvius (Italy). Journal of Geophysical Research: Solid Earth, 123, 6299-6317. https://doi.org/10.1029/2017JB015383

Tierz, P., Woodhouse, M. J., Phillips, J. C., Sandri, L., Selva, J., Marzocchi, W., \& Odbert, H. M. (2017). A framework for probabilistic multi-hazard assessment of rain-triggered lahars using Bayesian Belief Networks. Frontiers in Earth Science, 5, 73.

Tinti, S., Armigliato, A., Pagnoni, G., \& Zaniboni, F. (2005). Scenarios of giant tsunamis of tectonic origin in the Mediterranean. ISET Journal of Earthquake Technology, 42, 171-188.

Tinti, S., Armigliato, A., Tonini, R., Maramai, A., \& Graziani, L. (2005). Assessing the hazard related to tsunamis of tectonic origin: A hybrid statistical-deterministic method applied to Southern Italy Coasts, ISET. Journal of Earthquake Technology, 42(189), 201.

Tinti, S., Chiocci, F. L., Zaniboni, F., Pagnoni, G., \& de Alteriis, G. (2011). Numerical simulation of the tsunami generated by a past catastrophic landslide on the volcanic island of Ischia, Italy. Marine Geophysical Researches, 32, 287-297.

Tinti, S., Maramai, A., \& Graziani, L. (2004). The new catalogue of Italian Tsunamis. Natural Hazards, 33(439), 465.

Tinti, S., Pagnoni, G., \& Piatanesi, A. (2003). Simulation of tsunamis induced by volcanic activity in the Gulf of Naples (Italy). Natural Hazards and Earth System Sciences, 3, 311-320.

Vannucci, G., \&Gasperini, P. (2004). The new release of the database of Earthquake Mechanisms of the Mediterranean Area (EMMA Version 2). Annals of Geophysics, 47(1), 307-334.

Volpe, M., Lorito, S., Selva, J., Tonini, R., Romano, F., \& Brizuela, B. (2019). From regional to local SPTHA: Efficient computation of probabilistic tsunami inundation maps addressing near-field sources. Natural Hazards and Earth System Sciences, 19, 455-469. https:// doi.org/10.5194/nhess-19-455-2019

Wang, X., \& Liu, P. L. F. (2005). A numerical investigation of Boumerdes-Zemmouri (Algeria) earthquake and tsunami. CMES, 10(2), $171-183$

Wang, X., \& Liu, P. L. F. (2006). An analysis of 2004 Sumatra earthquake fault plane mechanisms and Indian Ocean tsunami. Journal of Hydraulic Research, 44(2), 147-154. https://doi.org/10.1080/00221686.2006.9521671

Ward, S. N. (2001). Landslide tsunami. Journal of Geophysical Research, 6, 11201-11215. https://doi.org/10.1029/2000JB900450

Watts, P., Grilli, S. T., Kirby, J. T., Fryer, G. J., \& Tappin, D. R. (2003). Landslide tsunami case studies using a Boussinesq model and a fully nonlinear tsunami generation model. Natural Hazards and Earth System Science, 3(5), 391-402.

Watts, P., Grilli, S. T., Tappin, D. R., \& Frye, G. J. (2005). Tsunami generation by submarine mass failure. II: Predictive equations and case studies. Journal of Waterway, Port Coastal, and Ocean Engineering, 131(298), 298-310.

Wells, D., \& Coppersmith, K. (1994). New empirical relationships among magnitude, rupture length, rupture width, rupture area, and surface displacement. Bulletin of the Seismological Society of America, 84(4), 974-1002. 